FEDERAL

RESERVE

BANK of

RESEARCH DIVISION

Working Paper Series

ST. LOUIS

\title{
Labor Market Upheaval, Default Regulations, and Consumer Debt
}

\author{
Kartik Athreya, \\ Juan M. Sánchez, \\ Xuan S. Tam \\ and \\ Eric R. Young
}

\author{
Working Paper 2014-002C \\ https://doi.org/10.20955/wp.2014.002
}

October 2014

\section{FEDERAL RESERVE BANK OF ST. LOUIS \\ Research Division \\ P.O. Box 442 \\ St. Louis, MO 63166}

The views expressed are those of the individual authors and do not necessarily reflect official positions of the Federal Reserve Bank of St. Louis, the Federal Reserve System, or the Board of Governors.

Federal Reserve Bank of St. Louis Working Papers are preliminary materials circulated to stimulate discussion and critical comment. References in publications to Federal Reserve Bank of St. Louis Working Papers (other than an acknowledgment that the writer has had access to unpublished material) should be cleared with the author or authors. 


\title{
Labor Market Upheaval, Default Regulations, and Consumer Debt*
}

\author{
Kartik Athreya $^{\dagger} \quad$ Juan M. Sánchez ${ }^{\ddagger} \quad$ Xuan S. Tam ${ }^{\S} \quad$ Eric R. Young ฯ
}

August 7, 2014

\begin{abstract}
In 2005, reforms made formal personal bankruptcy much more costly. Shortly after, the US began to experience its most severe recession in seventy years, and while personal bankruptcy rates rose, they rose only modestly given the severity of the rise in unemployment. By contrast, informal default through delinquency rose sharply. In the subsequent recovery, households have been widely viewed as "deleveraging" (Mian and Sufi 2011, Krugman and Eggertson 2012) via the largest reduction of unsecured debt seen in the past three decades. We measure the relative roles of recent bankruptcy reform and labor market risk in accounting for consumer debt and default over the Great Recession. Our results suggest that bankruptcy reform likely prevented a substantial increase in formal bankruptcy filings, but had only limited effect on informal default from delinquencies, and that changes in job-finding rates were central to both.

Keywords: Delinquency, Personal Bankruptcy, Unsecured Debt, Job Separation, Job Finding.
\end{abstract}

JEL Codes: D9, E21, K35

${ }^{*}$ We thank various seminar and conference participants, and especially the anonymous referee and our discussant, Dean Corbae, for insightful comments. The views expressed here are solely those of the authors and not necessarily those of the Federal Reserve Banks of Richmond or St. Louis or the Federal Reserve System. Young thanks the Bankard Fund for Political Economy at the University of Virginia for financial support.

${ }^{\dagger}$ Corresponding author. Research Department, Federal Reserve Bank of Richmond, kartik.athreya@rich.frb.org.

¥ Research Department, Federal Reserve Bank of St. Louis, sanchez@stls.frb.org.

$\S$ Department of Economics and Finance, City University of Hong Kong, xuanstam@cityu.edu.hk.

` Department of Economics, University of Virginia, ey2d@virginia.edu. 


\section{Introduction}

During the Great Recession and in the subsequent recovery, households have defaulted on consumer (non-mortgage) debt at high rates, and have also been widely viewed as "deleveraging" (Mian and Sufi 2011, Eggertson and Krugman 2012, Guerrieri and Lorenzoni 2010). Deleveraging is an interpretation consistent with the largest reduction in the volume of unsecured debt in the past several decades. Figure 1 shows that between 2009 and 2012 credit card debt decreased by about $\$ 160$ billion. $^{1}$

Perhaps the defining characteristic of the Great Recession has been the effect it has had on the labor market experiences of U.S. households. Figure 2 displays the paths taken by two series that convey the increase in volatility experienced by the typical household in an essentially selfexplanatory manner.

Lastly, along with household deleveraging and labor market risk, recent years have seen (perhaps naturally) a substantial rise in overall default on unsecured consumer debt. Moreover, the data show a shift in the relative importance of formal bankruptcy and informal "delinquency" as pathways to default. Figure 3 shows how delinquency (measured as a fraction of total consumer debt) and bankruptcy rates have evolved over the eight years from 2004 to 2012. As for default related patterns, an event whose importance we will evaluate is the "The Bankruptcy Abuse Prevention and Consumer Protection Act" (BAPCPA), enacted in late 2005. Importantly, this act altered the relative costs of delinquency and bankruptcy in favor of the former. At an aggregate level, we see from the figure that immediately prior to the enactment of BAPCPA, there was a sharp spike in bankruptcies followed by a sharp collapse. Intuitively, this is related to the advancement of filings prior to the increase in bankruptcy costs by all those close to the margin.

The very large change in labor market risk faced by households during the Great Recession and subsequent recovery, and the immediate precedent of the 2005 bankruptcy reform, together created conflicting forces that certainly complicate any purely empirical analysis of the data described above. This is especially true of any more narrow analysis of the effect of the fairly novel bankruptcy reform. In particular, the relative costliness of delinquency fell as a result of the reform, while the share of households faring poorly in the labor market rose, both of which could, all else equal, be expected to increase default rates while shifting the form of default away from formal bankruptcy. At the same time, those households not experiencing immediate misfortune in the labor market faced stronger incentives to increase their net asset position to deal with greater ambient labor market risk. For some, this change would come from lowering debt (deleveraging), while for others, precautionary balances would grow. At the same time, costlier bankruptcy, all else equal, could be expected relax supply-side constraints and encourage household borrowing, just as would the increased proportion of households trying to smooth through labor-market-related misfortune in a recession. As a result, it is entirely possible that deleveraging during the Great Recession might well have been more substantial, were bankruptcy reform not enacted shortly prior to it.

In this paper, our aim is to answer the following question: How much did changes in labor market risk (as measured by job separation and finding rates), along with recent bankruptcy reform, alter the paths of bankruptcy, delinquency, loan pricing, and unsecured credit use over the Great

\footnotetext{
${ }^{1}$ Source: http://www.newyorkfed.org/microeconomics/hhdc.html\#2013/q3
} 
Recession? In particular, to what extent can these forces help us understand observed deleveraging? In other words, how do the forces of job separation and job finding that yield the paths seen Figure 2 matter for the credit market outcomes seen in Figures 3 and 1?

Recent empirical work suggests that it might well have done so. Morgan (2012) estimates an empirical model of aggregate bankruptcy filings using income and unemployment aggregates. His findings suggest that the filing rate observed after the recession was substantially lower than would have been predicted by the behavior of aggregates alone. In other words, the regime does appear to have changed. ${ }^{2}$ In addition, Lawless et al. (2008) document the "missing bankrupts," the roughly 800,000 households who were predicted to file pre-reform but who did not.

We proceed by extending the life cycle model of Athreya et al. (2013) to allow for aggregate fluctuations in labor market risk. The resulting model is novel in being the first, to our knowledge, to allow for bankruptcy, delinquency, and business cycles simultaneously; specifically, we add an aggregate shock that moves between "steady state," "expansion," "recession," and "crisis" and alters the job finding and job separation rates, with durations that roughly capture the experience of the US during the period 2004-2011. As a result, we are the first to provide a transitional account of the effect of bankruptcy policy on observed default behavior. ${ }^{3}$ We first calibrate our model to represent the economy before BAPCPA, corresponding to the year 2004 . We then compute the model's predictions for the paths of labor market and credit market variables in response to BAPCPA being announced one period in advance and then enacted, along with the observed movements in hiring and separation rates. To execute the latter experiment, we parameterize the model to match the dynamics of employment and unemployment duration by exploiting the mechanical relationship between these objects and the job finding and job separation rates. We then ask what would have happened if BAPCPA had not been implemented.

Our model's main implication is that BAPCPA likely prevented a substantial increase in bankruptcy filings, but had only a limited effect on the observed path of delinquencies. Thus, the reform appears to have "worked" - in the narrow sense that it did not encourage households to find alternative routes to default and still reduced default overall, given the path of aggregate labor market outcomes. Our results suggest also that the level of defaults would fall in absolute terms if the labor market had not experienced substantial negative shocks over the same time frame.

We then isolate the effect of the two different types of labor market shocks in our model: shocks to the job finding rate, and those to the separation rate. We do this through two counterfactual exercises where we shut off, in turn, variation in either the job offer rate and the separation rate. Our main finding here is that the fluctuations in the separation rate observed over the Great Recession did not significantly affect the dynamics of default; all of the work is done by the large decline in the job-finding rate. In the absence of declines in hiring, our model suggests that BAPCPA would have produced a persistent decline in bankruptcy filings and no response in delinquency.

\footnotetext{
${ }^{2}$ He also finds that the ratio of Chapter 7 "liquidation" bankruptcies to Chapter 13 "reorganization" bankruptcies reverted very quickly to the pre-reform level. This reversion suggests that the reform did not lower Chapter 7 bankruptcy-whereby unsecured debts are fully discharged-by merely diverting borrowers into Chapter 13.

${ }^{3}$ Our model of delinquency is related to, but distinct from, the recent model of Benjamin and Mateos-Planas (2012), who focus on steady states, and Gordon (2013), who studies only bankruptcy but with aggregate shocks. Chatterjee and Gordon (2012) also have an alternative debt relief procedure, but it involves voluntary wage garnishment; see also Chen (2013).
} 
The remainder of the paper is organized as follows. In section 2 , we present the main model. Section 3 describes the model parameterization of the steady state. Section 4 explains the main mechanisms at work in the model. Section 5 presents the results for the transition during the Great Recession. Section 6 concludes.

\section{Model}

Our baseline model starts with our earlier work in Athreya et. al. (2013). The environment features a continuum of finitely lived households who face idiosyncratic risks that they are unable to completely insure. A central aspect of our representation of this risk is that households face both wage and employment uncertainty, and follows recent work of Low, Meghir, and Pistaferri (2010). For the high frequencies (quarterly) over which we aim to understand debt and default dynamics, such a distinction is essential; for short periods, individuals may simply not be able to match with employers (firms), and in these instances, the loss of income may lead them to find delay in payment useful, with longer runs of misfortune leading to formal bankruptcy. Our model of the labor market also allows for quits as a source of separation.

Households live for a finite number of periods and are born into the model as adult workers (when they are 22 years old), they work until retirement (age 62), and exit the model with certainty at age 72 . Households have access to a risk-free savings instrument and may borrow. Borrowing confers two options on individuals. First, they may elect, ex-post, to formally repudiate all debt by obtaining a formal discharge in bankruptcy court from all debt obligations. Under formal bankruptcy, filing households must pay a formal cost of filing to reflect use of legal resources, as well as transactions costs associated with diminished access to various forms of payments and short-term credit (such as rental of housing and consumer durables). They also are allowed to face other costs associated with the procedure, potentially including "social stigma" or other penalties. Second, borrowers may simply cease debt payment without receiving a formal discharge. In this case, debtors pay costs, but also have their debts renegotiated to reflect the household's ability to refinance loans with other lenders. In what follows, capital letters are used for functions, lower case letters for variables, and Greek letters for parameters.

\subsection{Endowments and Market Arrangement}

Each model period represents one quarter of real time. The relatively high frequency of this model creates some problems with respect to tractability, which in turn will lead to impose some simplifications with respect to our model of labor income risk and transitional paths for exogenous variables. ${ }^{4}$ However, it is essential to capture the high-frequency risks that agents face, and to not restrict borrowers to durations of debt that are far longer that the duration of time between the receipt of various shocks to labor income. Similarly, with respect to delinquency, it is clear that

\footnotetext{
${ }^{4}$ Most seriously, storage requirements are substantial. Given the life-cycle nature of the model, we must track the decision rules of households throughout their lives. Due to the short length of a period relative to agent lifetimes, we must store a large number of decisions rules (in our setting, agents live for over 200 model periods). And due to the rich set of shocks that affect agents, the cardinality of our state space is very large.
} 
borrowers have the option to fall behind on debt repayments to an extent that is similar (e.g., "90 days past-due") to durations that are not simply equivalent to permanent default.

Households vary in their formal educational attainment, $e$, and their age, $a$, both of which affect their productivity $n$ when working. Education also affects the likelihood of reemployment when unemployed. To reflect varied match quality between workers and firms, match-specific productivity varies and is denoted by $m$. Given these parameters, wages $w(e, a, n, m)$ are given by

$$
\ln \left(w_{a}(e)\right)=x_{a}(e)+n_{a}+m_{a}
$$

where $x_{a}$ is the deterministic age income profile and $n_{a}$ is a random walk:

$$
n_{a}=n_{a-1}+\zeta_{a}
$$

with $\zeta_{a} \sim N\left(0, \sigma_{\zeta}^{2}(e)\right)$ and $m_{a} \sim N\left(0, \sigma_{m}^{2}(e)\right)$. Workers are matched with firms with productivity that depends on a match-specific component that changes only when the worker changes firm. Note that firms do not differ in their productivity. Rather, workers at any moment in time belong in a particular match that determines (in part) their productivity. New draws of match quality come from a normal distribution with mean 0 and variance $\sigma_{m}^{2}$. To simplify notation we refer simply to $(e, a, n, m)$ as $(\mathbb{I})$. Households may also suffer shocks that lead to disability in which they permanently cannot supply labor. In this case, they receive transfers that will be specified further below.

Under our specification, disposable earnings of a household of age $a$, with productivity $n$, firmworker match-specific component $m$, who are not currently obtaining disability insurance are given by

$$
\mathbf{y}(\mathbb{I}, p)=p(w(\mathbb{I}) h(1-\tau)-F(e)),
$$

where $h$ is the fixed number of hours, $\tau$ is the proportional tax rate that used to finance all the social programs, and $F(e)$ is the fixed cost of commuting to work. Labor is subject to search frictions, whereby a job offer arrives with probability $\lambda^{E}(e)$ if the household is employed and $\lambda^{N}(e)$ if the household is unemployed. When an offer is available, workers decide to work or not, and this decision is denoted by $p=1$ or $p=0$, respectively. If a new work opportunity arises, workers decide whether to switch jobs or not. When employed, all worker-firm matches are subject to exogenous separation at rate $\delta(e)$. Additionally, workers can quit (to pursue other employment opportunities, among other things).

There is a social safety net that partially insures workers against the risk of unemployment and the risk of permanent loss of productivity. The former arises from search frictions, and the latter arises as individuals face the risk of becoming disabled, an aobsrobing state in which their productivity falls to zero. Households receive unemployment payments the first period they are unemployed, only if they did not quit, and continue to receive work offers (stochastically); UI benefits are a fraction $\vartheta$ of wages up to a maximum cap $\Xi$. Disability is an absorbing state, and individuals that are eligible decide whether to apply for disability insurance or not. An individual is eligible to apply for disability if he is older than 50 years old, unemployed, and didn't apply for disability the last period - the success rate of applications is given by $\chi \in[0,1]$, and disability insurance is asset-tested at breakpoints $\left(a_{1}, a_{2}, a_{3}\right)$ with declining benefits. Lastly, individuals are 
eligible receive food stamps, modeled simply as an increment to income, rather than a voucher for a specific consumption good; $\Gamma$ is the maximum food stamp benefit. We summarize all government transfers by the function $T(\mathbf{y})$.

\subsection{Preferences}

The period utility function is

$$
U(c, p)=\frac{(c \exp (\varphi p))^{1-\gamma}}{1-\gamma}
$$

where $c \in \mathbb{R}_{+}$stands for consumption. $\varphi<0$ captures the disutility of labor supply. Households have a constant discount factor $\beta<1$, and $\gamma \geq 0$ is the coefficient of relative risk aversion. Households of age $a$ survive to age $j+1$ with probability $\varsigma(e, j)$.

\subsection{Value Functions}

Let $l \in\{U, O, H\}$ denote the current labor market status of a household. The value function of a household that is unemployed $(l=U)$, or does have a job offer $(l=O)$, or is currently in disability insurance $(l=H)$ is

$$
V^{l}(b, \mathbb{I}, u, s)=\max \{\underbrace{B^{l}(b, \mathbb{I}, u, s)}_{\text {bankruptcy }}, \underbrace{D^{l}(b, \mathbb{I}, u, s)}_{\text {delinquency }}, \underbrace{P^{l}(b, \mathbb{I}, u, s)}_{\text {solvency }}\} .
$$

First, we present the case in which the household files for bankruptcy. The function $B^{O}(a, n, m)$ is the value of lifetime utility for a household with a job offer from a firm with match-specific component $m$, whose age is a years old, has productivity $n$, and that files for bankruptcy.

$$
B^{O}(a, n, m)=\max _{p}\left\{U(\mathbf{y}(\mathbb{I}, 1)+T(\mathbf{y})-\Delta(1), 1)-\psi_{B}+\beta \mathbb{E}\left[V^{l^{\prime}}\left(0, a+1, n^{\prime}, m^{\prime}, p, 0\right) \mid l, n, p\right]\right\}
$$

The first part on the right-hand side is the period utility. The first term inside the utility function is current consumption, which in this case is simply income plus transfers minus the cost of filing $\Delta(e)$ (which depends on employment status as some costs can be waived). The second term in the utility function equals 0 , if the household chooses not to work, and 1 , if the household works. The second cost of bankruptcy on the right-hand side is $\psi_{B}$, which will be set to reflect all other costs through a single nonpecuniary term. The last part on the right hand side is the expected discounted utility from the next period. In this case the expectation is over $\left(n^{\prime}, l^{\prime}, m^{\prime}\right)$. The expectation over the next period productivity is conditional on this period productivity because there is persistence in productivity. The expectation on the next period labor status is conditional on this period status $l$ and $p$ because households that work this period are more likely to have an offer the next period than unemployed households. Finally, the expectation is also over $m^{\prime}$ because workers receive an offer with probability $\lambda^{E}(e)$ from other firms with match-specific component $m^{\prime}$. Importantly, notice that in the case of filing for bankruptcy a household starts the next period with zero debt. 
The function $B^{U}(a, n, u, s)$ is the value of lifetime utility for a household filing for bankruptcy without a job, whose age is $a$ years old, productivity is $n$, and has flags representing eligibility for unemployment insurance and disability insurance, $u$ and $s$, respectively:

$B^{U}(a, n, u, s)=\max _{d}\left\{U(U I(\mathbb{I}) u+T(U I)-\Delta(0), 0)-\psi_{B}+\beta \mathbb{E}\left[V^{l^{\prime}}\left(0, a+1, n^{\prime}, 0, s(1-d)\right) \mid l, n, 0, s, d\right]\right\}$

Notice that the income of this household comes from food stamps $T$, and unemployment insurance $U I$ only if $u=1$. The last part in the right-hand side represents the expected discounted lifetime utility from the next period. The expectation is taken over $\left(n^{\prime}, l^{\prime}, m^{\prime}\right)$. Importantly, the expectation over the labor status next period $l^{\prime}$ is conditional on $s \times d$. This is the case because households that are eligible to apply for disability insurance, $s=1$, that decide to apply, $d=1$, may enter the disability status $H$ from tomorrow or stay unemployed, in which case $s^{\prime}=s(1-d)=0$; households that are not eligible, $s=0$, or decide not to apply, $d=0$, can either get a job offer, with probability $\lambda^{U}$, or stay unemployed. Notice that both households that receive unemployment payments this period, $u=1$, and those that are not eligible this period, $u=0$, will not be eligible the next period, $u^{\prime}=0$, because unemployment insurance payments are available only for one period. Again in this case, because the household files for bankruptcy, we have that $b^{\prime}=0$.

The last possible labor market status for a household filing bankruptcy is being in disability insurance. The function $B^{H}(a, n)$ represents the value of lifetime utility for a household filing for bankruptcy that is in disability insurance with productivity $u$ and age $a$.

$$
B^{H}(a, n)=U(D B(\mathbb{I})+T(D B)-\Delta(0), 0)-\psi_{B}+\beta V^{H}(0, a+1, n)
$$

In this case, the household receives disability payments $D B$ and food stamps $T$. The discounted lifetime utility from tomorrow on is very simple: disability is an absorbing state and the income will be constant forever. As in the previous cases, since the household files for bankruptcy, we have that $b^{\prime}=0$.

For the cases of credit status equal to delinquency $(D)$ and solvency $(S)$, the transitions regarding the labor market are exactly the same as in the case of bankruptcy. Thus, we will explain only the part that has to do with the credit status. Further, to simplify notation, hereafter we do not explicitly write the variables that are used to condition in the expectation.

The three possible labor market statuses $(O, U, H)$ for the case of delinquency are presented below.

$$
\begin{aligned}
D^{O}(a, n, m) & =\max _{p}\left\{U(\mathbf{y}(\mathbb{I}, p)(1-p \eta)+T(\mathbf{y}), p)-\psi_{D}+\beta \mathbb{E}\left[V^{l^{\prime}}\left(h^{O}(\mathbb{I}), a+1, n^{\prime}, m^{\prime}, p, 0\right)\right]\right\} \\
D^{U}(a, n, u, s) & =\max _{d}\left\{U(U I(\mathbb{I}) u+T(U I), 0)-\psi_{D}+\beta \mathbb{E}\left[V^{l^{\prime}}\left(h^{U}(\mathbb{I}, u, s, d), a+1, n^{\prime}, 0, s(1-d)\right)\right]\right\} \\
D^{H}(a, n) & =U(D B(\mathbb{I})+T(D B), 0)-\psi_{D}+\beta V^{H}\left(h^{H}(a, n), a+1, n\right)
\end{aligned}
$$

Notice that there are only three differences with the case of bankruptcy. First, instead of a fixed cost of filing, there is a fraction of income that is garnished, $\eta$, only in the case in which the household works. The second difference is that the utility cost of delinquency is $\psi_{D}$. Finally, notice 
that in this case the households start the next period with debt $b^{\prime}=h$. The household takes the function $h$ as given. In the section that describes the credit market we explain how it is determined.

Finally, we present the value functions for a household that decides to make his debt payments. The key difference with the previous case is that the current stock of debt, $b$, is also a state variable, and households choose the next period debt, $b^{\prime}$ :

$$
\begin{aligned}
P^{O}(b, a, n, m) & =\max _{p, b^{\prime}}\left\{U\left(\mathbf{y}(\mathbb{I}, p)+T(\mathbf{y})+b-b^{\prime} q^{E}\left(b^{\prime}, \mathbb{I}\right), p\right)+\beta \mathbb{E}\left[V^{l^{\prime}}\left(b^{\prime}, m^{\prime}, p, 0\right)\right]\right\} \\
P^{U}(b, a, n, u, s) & =\max _{d, b^{\prime}}\left\{U\left(U I(\mathbb{I}) u+T(U I)+b-b^{\prime} q^{U}\left(b^{\prime}, \mathbb{I}, u, s, d, 0\right)\right)+\beta \mathbb{E}\left[V^{l^{\prime}}\left(b^{\prime}, 0, s(1-d)\right)\right]\right\} \\
P^{H}(b, a, n) & =\max _{b^{\prime}}\left\{U\left(D B(\mathbb{I})+T(D B)+b-b^{\prime} q^{H}\left(b^{\prime}, \mathbb{I}\right), 0\right)+\beta V^{H}\left(b^{\prime}, a+1, n\right)\right\}
\end{aligned}
$$

The key difference in this case is that the consumption today has an extra term, $b-b^{\prime} q^{l}\left(b^{\prime}, \mathbb{I}\right)$, that represents the extra funds available after repaying the debt, $b$, and new borrowing $b^{\prime} q$. In the next period, this household will have debt obligations $b^{\prime}$.

Before presenting the pricing in credit market, it is useful to define the policy functions describing the households decision regarding repayment of obligations. Let $\mathbf{1}^{l, m}(b, \mathbb{I}, u, s)$ be a policy function that is 1 if a household in state $l \in\{O, U, H\}$ makes repayment decision $m \in\{P, B, D\}$, and zero otherwise.

\subsection{Loan pricing}

Pricing of credit in this model arises from the condition that lenders earn zero expected profits on any loan. Households issue one-period bonds with face value $b$, and they may decide next period whether to (i) repay the loan as promised, (ii) file for bankruptcy and obtain a discharge from debt, or (iii) refuse to pay and have the new face value of debt reset according to the rule $b^{H}(b, \mathbb{I})$, as explained below.

The price function in the case of saving, $b \geq 0$, is given by

$$
q\left(b^{\prime}, \mathbb{I}\right)=\frac{\varsigma(e, j)}{1+r}
$$

where $r$ is the risk-free rate. However, when households borrow, $b<0$, the price function will be the solution to a functional equation. In particular, this function will solve

$$
q\left(b^{\prime}, \mathbb{I}\right)=\varsigma(e, j) \frac{\mathbb{E}\left[Q_{p a y}+Q_{d q}\right]}{1+r+\phi},
$$

where $\phi$ is a transaction cost of intermediation that applies only to borrowing, and

$$
Q_{\text {pay }}=\mathbf{1}^{O, P}\left(b^{\prime}, \mathbb{I}^{\prime}, u^{\prime}, s^{\prime}\right)+\mathbf{1}^{U, P}\left(b^{\prime}, \mathbb{I}^{\prime}, u^{\prime}, s^{\prime}\right)+\mathbf{1}^{H, P}\left(b^{\prime}, \mathbb{I}^{\prime}, u^{\prime}, s^{\prime}\right)
$$




$$
\begin{aligned}
Q_{d q} & =\frac{\mathbf{1}^{O, D}\left(b^{\prime}, \mathbb{I}^{\prime}, u^{\prime}, s^{\prime}\right)}{b^{\prime}}\left(q^{O}\left(b^{O}\left(b^{\prime}, \mathbb{I}^{\prime}\right), \mathbb{I}^{\prime}, u^{\prime}, s^{\prime}\right) b^{O}\left(b^{\prime}, \mathbb{I}^{\prime}\right)+\eta \mathbf{y}(\mathbb{I})\right)+ \\
& \left.\frac{\mathbf{1}^{U, D}\left(b^{\prime}, \mathbb{I}^{\prime}, u^{\prime}, s^{\prime}\right)}{b^{\prime}} q^{U}\left(b^{U}\left(b^{\prime}, \mathbb{I}^{\prime}\right), \mathbb{I}^{\prime}, u^{\prime}, s^{\prime}\right)\right) b^{U}\left(b^{\prime}, \mathbb{I}^{\prime}\right)+ \\
& \left.\frac{\mathbf{1}^{H, D}\left(b^{\prime}, \mathbb{I}^{\prime}, u^{\prime}, s^{\prime}\right)}{b^{\prime}} q^{H}\left(b^{H}\left(b^{\prime}, \mathbb{I}^{\prime}\right), \mathbb{I}^{\prime}, u^{\prime}, s^{\prime}\right)\right) b^{H}\left(b^{\prime}, \mathbb{I}^{\prime}\right)
\end{aligned}
$$

Next period the lender recovers one good in each state $\mathbb{I}^{\prime}$ in which the borrower chooses to repay (the first term). The last term collects the states tomorrow in which the borrower goes delinquent and is not working tomorrow; the lender adjusts the existing debt to $b^{H}\left(b^{\prime}, \mathbb{I}\right)$ and values it at the market price $q\left(b^{H}\left(b^{\prime}, \mathbb{I}\right), \mathbb{I}^{\prime}\right)$. The second term describes the value of the contract in states in which the borrower goes delinquent tomorrow and is working $\left(p\left(\mathbb{I}^{\prime}\right)=1\right)$, permitting additional resources to be recovered through wage garnishment. States in which the household goes bankrupt are not included, because the lender receives nothing in those states.

As in Athreya et al. (2013), lenders optimize, and therefore adjust the existing debt to maximize the value of expected repayments:

$$
b^{l}(\mathbb{I})=\underset{h}{\operatorname{argmax}}\left\{q^{l}(h, \mathbb{I}) h\right\} ;
$$

as $h$ increases, $q$ decreases (since the probability of a bankruptcy or continued delinquency increases), so the lender is trading off the face value of the debt for the likelihood of repayment (reflected in q). Athreya et al. (2013) contains a brief discussion how the absence of commitment to terms would lead lenders to always adjust debt according to (3).

\section{Parameterization}

Our baseline model parameters are given below in Tables 1, 2, and 3. Table 1 flows from Low, Meghir, and Pistaferri (2010) and collects parameters that are assigned directly (i.e., not calibrated to match any target). Because our model differs from theirs in terms of the credit market, the implied path of labor market variables will not coincide exactly with those obtained in that paper, but it turns out that the differences are minor.

Tables 2 gathers non-calibrated parameters central to default and borrowing, such as the riskfree interest rate, transactions cost of finance, and the direct costs of bankruptcy (fees, etc.). These correspond to standard values in the literature-a risk-free savings rate of 1.5 percent when annualized, and a transactions costs that is approximately 3 percent annually as measured by Evans and Schmalensee (1999), for example.

As noted previously, we allow the filing fee to depend on employment status because it is possible for households to avoid paying some fees during filing (such as filing pro se or receiving pro bono legal aid), while other fees can be waived for need. We set $\eta=0$, based on evidence that wage garnishment is rarely effective (White 1997).

Table 3 collects the three parameters that are calibrated in the model, and Table 4 lists the main calibration targets. 
Table 1: Low-Meghir-Pistaferri Parameters

\begin{tabular}{|l|c|c|c|}
\hline \hline & & High Edu. & Low Edu. \\
\hline Education distribution & $\Upsilon$ & 0.568 & 0.432 \\
\hline Std. deviation of permanent shock & $\sigma_{\zeta}$ & 0.106 & 0.095 \\
\hline Std. deviation of firm-worker shock & $\sigma_{m}$ & 0.229 & 0.226 \\
\hline Job separation rate & $\delta$ & 0.023 & 0.040 \\
\hline Job arrival rate in unemployment & $\lambda^{N}$ & 0.709 & 0.657 \\
\hline Job arrival rate in employment & $\lambda^{E}$ & 0.623 & 0.579 \\
\hline Fixed cost of work & $F$ & $\$ 1,213$ & $\$ 1,088$ \\
\hline Disutility of working & $\varphi$ & -0.620 & -0.550 \\
\hline Total hours of work & $h$ & 500 & 500 \\
\hline UI replacement ratio & $\vartheta$ & 0.750 & 0.750 \\
\hline UI cap & $\Xi$ & $\$ 2,384$ & $\$ 2,384$ \\
\hline DI application success rate & $\chi$ & 0.500 & 0.500 \\
\hline Maximum food stamp & $\Gamma$ & $\$ 800$ & $\$ 800$ \\
\hline DI threshold 1 & $a_{1}$ & $\$ 1,203$ & $\$ 1,203$ \\
\hline DI threshold 2 & $a_{2}$ & $\$ 7,260$ & $\$ 7,260$ \\
\hline DI threshold 3 & $a_{3}$ & $\$ 16,638$ & $\$ 16,638$ \\
\hline
\end{tabular}

Table 2: Other Parameters

\begin{tabular}{|l|c|c|}
\hline Risk-free interest rate & $r$ & $0.375 \%$ \\
\hline Lending cost & $\phi$ & $0.75 \%$ \\
\hline BK filing fee for $p=1$ & $\Delta$ & $\$ 1,200$ \\
\hline BK filing fee for $p=0$ & $\Delta$ & $\$ 600$ \\
\hline Risk aversion & $\gamma$ & 2.0 \\
\hline
\end{tabular}

Table 3: Calibrated Parameters

\begin{tabular}{|l|c|c|}
\hline \hline Discount factor & $\beta$ & 0.947 \\
\hline Non-pecuniary cost | BK & $\psi_{B}$ & 1.785 \\
\hline Non-pecuniary cost | DQ & $\psi_{D}$ & 0.103 \\
\hline
\end{tabular}

Table 4: Calibration Fit

\begin{tabular}{|l|c|c|}
\hline \hline & Data & Model \\
\hline \hline Share of debt in 90+ DQ, \% & 8.9 & 8.9 \\
\hline Bankruptcy rate, \% & 0.26 & 0.25 \\
\hline Mean (assets/income) & 4.07 & 3.09 \\
\hline
\end{tabular}

Overall, the model does well, and because of our use of the detailed wage and social insurance setting of Low, Meghir, and Pistaferri (2010), we are assured that the model represents risks and safety nets in a comprehensive manner as well. In utility terms, bankruptcy is more costly than delinquency; as noted in our other work, this condition is necessary for both types of default to 
coexist in equilibrium because delinquency generates a smaller continuation value. Of course, the household will pay the cost $\psi_{D}$ every period of delinquency, rather than only once as with $\psi_{B}$, so the expected duration of delinquency matters for determining which option is ultimately more costly. If we convert the utility costs into consumption units, the cost of bankruptcy is 2.03 percent of mean consumption, while the cost of delinquency is only 0.12 percent.

Two other relevant facts, neither of which is targeted, are: (i) the median age of defaulters and (ii) the fraction of borrowers in the model. For the former, the median age in the model is 35.36, relative to the empirical counterpart of 41 years, as measured in Sullivan, Warren, and Westbrook (2000). For the latter, the model features a proportion of borrowers of 15.27 percent, similar to the measure reported by Wolff (2006) of 17.6 percent. Lastly, as we will show further below, the fit of the path of income in the model is good as well, again despite not being a target for the calibration. The benchmark model appears reasonable along relevant dimensions.

\section{Understanding delinquency and bankruptcy decisions}

To understand behavior in the transitions of interest, we first describe decision rules. For convenience of exposition, we show results for the various realizations of the match quality shock $m$; the results are essentially identical when using the other wage shock in the model, $n$. We begin by comparing three agents, all of whom are 33.5 years old, and all of whom have high education, in the three panels in the left-hand column of Figure 4. A first point is that this type of borrower, if they have high match-specific quality $\left(m=m_{h i}\right)$, finds bankruptcy better than delinquency in the sense that she transitions to it without passing through delinquency (the dashed red line). To understand the decision of a borrower with respect to repayment, it is essential to know the relative benefits associated with repayment, delinquency and bankruptcy. In the middle panel, we display the implied interest rate arising from a delinquency. If the revised amount, $h$, is smaller than the initially-owed face value of debt, this rate is negative, and reflects debt forgiveness. Conversely, if $h$ is bigger than $b$, lenders have imposed a "penalty" rate on the debt. As is clear, for low debts, irrespective of the wage shock, we see that delinquency generates a penalty rate of interest. Moreover, while debt forgiveness occurs only when debts are larger, it also occurs most when households are in bad shape with respect to income. The figure shows clearly that the amount of debt forgiven rises as the $m$ shock gets worse. In essence, borrowers with poor future income prospects get better deals out of delinquency: it is the lender's best response given an income-poor borrower's retention of the option of bankruptcy in which the unsecured lender would receive nothing at all.

Thus far, we have spelled out the terms in delinquency for all debt levels. But in order to make a decision on repayment, borrowers must compare this with the terms they would receive if they simply tried to roll over the debt instead of invoking either bankruptcy or delinquency. The bottom panel of Figure 4 displays the interest rates required to roll over current debt. In general, we see that the interest rises with the face value of debt that is due. However, notice the terms offered to the agent with the low $m$ shock - rolling over debt requires relatively high interest rates even when that option is optimal. It is interesting to note that the household begins to receive debt forgiveness (the curve in the middle panel crosses zero) before delinquency becomes optimal, because $\psi_{D}>0$. 
We know from the top panel that delinquency is also not chosen by the borrower with a good wage, i.e., someone whose $m=m_{h i}$. For this type of borrower, we see from the middle panel that the terms arising from delinquency are not ideal: it offers essentially no debt forgiveness, and instead saddles her with a penalty rate of interest for virtually all debt levels. Of course, the fact that this borrower is enjoying good fortune in the labor market makes refinancing debt cheap, as shown by the dashed red line in the bottom panel of Figure 4. This is why this agent repays debts, and then directly transitions to bankruptcy without ever passing through delinquency. In contrast, for an agent doing poorly in the current period, and for debt levels in excess of a given amount (in this case, roughly -0.35 units), there is no face value that the borrower can issue that, once lenders have appropriately discounted the debt, yields a flow of resources into the current period sufficient to roll over the debt. The model therefore implies that whether delinquency precedes bankruptcy or not depends on the path of shocks rather than simply being an intermediate step used by all who eventually repudiate debt through bankruptcy.

As seen in the right-hand column of Figure 4, decisions of those with low levels of educational attainment are very similar to their well-educated counterparts, at least qualitatively. In particular, high current wages lead to bankruptcy, low wages to delinquency. There are small quantitative differences between the two groups, as low-educated borrowers go default with slightly less debt than high-educated ones, and the interest rates they face are higher (especially for the low- $m$ borrower, who can effectively roll over only -0.25 units).

One can think of delinquency as implicitly rolling over debt at the implicit interest rate defined by $h$. In Athreya et al. (2013) we show that households that choose delinquency in equilibrium cannot pay a higher rate than if they chose to be solvent. At first glance, this condition seems counterfactual, since delinquent individuals do pay higher rates than solvent ones. However, one does not observe the interest rate that the delinquent household would have paid if they had been solvent, which may actually be infinite. As a result, the population of delinquent borrowers pay high rates relative to the population of solvent borrowers because they would face even higher rates if they tried to repay.

Having shown how debt and the forces that govern income (educational attainment and the shocks $m$ and $n$ ) alter borrowing conditions and repayment behavior, it is useful to document the borrowing and repayment decisions in terms of the more standard labor market indicators of shortand long-term unemployment. Figure 5 takes a representative case where borrowers are in their mid-30s and have high education and median values for $n$ and $m$, and separates them into three groups: currently employed, newly separated, and continuing (long-term) unemployed. We see that from the top-left panel that the long-term unemployed will go delinquent on nearly any debt they bring into the period, because they face very high costs of rolling over even small debts. The newly unemployed, in contrast, despite receiving relatively favorable terms in delinquency (they are receiving significant debt forgiveness), will choose bankruptcy if they default. This is seen in the top-right panel. Lastly, the bottom-right panel shows the effect of rolling over the debt on consumption; particularly for the employed, household consumption will be very low and thus the household will find default attractive, despite the costs. This panel makes clear how dependent consumption is on current labor market status. Therefore, even with access to credit, and the default option via both bankruptcy and delinquency, households remain exposed in equilibrium to 
labor market risks.

\section{The Great Recession}

Having shown the individual-level mechanisms, and having described equilibrium steady-state dynamics in our model, we turn now to our main goal of evaluating how recent bankruptcy reform and labor market dynamics during the Great Recession influenced consumer credit markets. As noted, we are particularly focused on outcomes related to observed deleveraging and default behavior, in a model where the latter can occur via both delinquency and bankruptcy. We therefore turn next to the transitional dynamics arising from the change in bankruptcy law in 2005 and the subsequent changes in labor market risks faced by households as the Great Recession took hold.

\subsection{Calibration and Transition}

To proceed, we will compare the paths of salient features of the underlying economy under two assumptions. In the first economy, which we will refer to as "reform," the costs of bankruptcy jump to, and remain at, their post-BAPCPA level; and in the second, they remain at their pre-BAPCPA level. We refer to this case as the "no-reform" economy.

In both cases, we need to confront individual borrowers with labor market conditions that reflect observed changes in separation and job finding rates under the post-BAPCPA policy environment, generate paths for debt and default, compare these paths to the ones coming from households experiencing the same paths for job separation and finding in the pre-BAPCPA era. The latter is the counterfactual exercise necessary to determine the role played by the reform in the Great Recession.

Recall that we calibrated our model to match the steady state of the model to the US credit market in 2004, using parameters that match labor market outcomes on average. Our strategy is to then announce the passage of BAPCPA in the last quarter of 2005, and it becomes law in the first quarter of 2006. For the post-BAPCPA costs, we increase the filing fee $\Delta(e)$ by 50 percent for both employed and unemployed filers. This is in line with a variety of estimates (e.g. Morgan 2012). We ignore the other significant component of the BAPCPA reform, namely the means-testing of income. We do so for two reasons. First, the means-test does not mean that high-income individuals cannot file for Chapter 7 , but only that they must pass a more stringent assessment; our model is not capable of matching the requirements of this assessment (which include items like precommitted expenses). Second, evidence from Lawless et al. (2008) shows that the income distribution of filers did not change significantly between 2001 and 2007, suggesting that the means-test aspect of the reform did not substantially affect filing.

There is a single quarter in which the reform is (perfectly) anticipated and, as a result, affects both the terms on which credit is available, as well as the readiness of those entering this period with significant debt to use bankruptcy over delinquency to default in advance of the change. We then hit the labor market with education-specific shocks to their job finding rate, $\left(\lambda^{E}, \lambda^{N}\right)$, as well as to the overall common rate of job destruction $\delta$. We approximate the time path with a step function that changes five times, at the dates specified in Figure (6). Figure (7) shows the exact 
paths we choose.

We shut off the shocks in 2011 and permit the economy to converge to the new steady state (which, due to the assumption of individualized pricing, happens very quickly).

To model household expectations about the aggregate state, we assume the following transition matrix:

\begin{tabular}{|l|c|c|c|c|c|}
\hline & SS & Expansion & Recession & Great Recession & Jobless Recovery \\
\hline Steady State & 0.854 & 0.083 & 0.063 & 0.000 & 0.000 \\
\hline Expansion & 0.031 & 0.948 & 0.021 & 0.000 & 0.000 \\
\hline Recession & 0.125 & 0.063 & 0.804 & 0.008 & 0.000 \\
\hline Great Recession & 0.042 & 0.000 & 0.083 & 0.875 & 0.000 \\
\hline Jobless Recovery & 0.125 & 0.000 & 0.100 & 0.000 & 0.775 \\
\hline
\end{tabular}

Thus, we have that the Great Recession (the state with the worst labor market conditions) is expected to last 8.0 quarters (compared to roughly 5 quarters for the regular recession state); combined with the Recession state, the expected length of the downturn is 5.58 quarters. ${ }^{5}$ The Great Recession cannot be entered except through the Recession state, and the economy cannot transition directly from the Great Recession to an expansion.

To summarize the experiment, the way we proceed is to hit the economy with shocks to both job finding and job separation rates. Recall that we assume that at each date these shocks occur, they are unanticipated, and the households use the transition matrix specified above to formulate expectations about future realizations. Recall also that we allow job finding rates to vary with educational attainment, which helps us capture the substantially different labor market experiences of the skilled and unskilled over the period in question.

In Table 5 we report the terminal steady state.

Table 5: Terminal Steady State

\begin{tabular}{|l|c|c|c|c|}
\hline \hline & \multicolumn{2}{|c|}{ Reform } & \multicolumn{2}{c|}{ No Reform } \\
\hline \hline & $2004 \mathrm{Q} 1$ & $2012 \mathrm{Q} 2$ & $2004 \mathrm{Q} 1$ & $2012 \mathrm{Q} 2$ \\
\hline DQ Debt Rate & $8.95 \%$ & $11.67 \%$ & $8.95 \%$ & $11.70 \%$ \\
\hline BK Rate & $0.25 \%$ & $0.23 \%$ & $0.25 \%$ & $0.345 \%$ \\
\hline Frac Borr & $15.27 \%$ & $12.86 \%$ & $15.27 \%$ & $11.81 \%$ \\
\hline Relative Debt Size to 04Q1 & 1.000 & 0.886 & 1.000 & 0.762 \\
\hline
\end{tabular}

As can be seen from Figure (7), the terminal steady state has a lower job finding rate and the same job separation rate as the initial steady state; the reform is the only other change. The result is fewer borrowers, less debt, roughly the same bankruptcy rate, and a higher rate of delinquency.

\footnotetext{
${ }^{5}$ To calculate this number, denote by $v_{i}$ the expected time spent in state $i$, where $i=1$ denotes Recession and $i=2$ denotes Great Recession. These values follow the recursion

$$
v_{1}=1+0.804 v_{1}+0.008 v_{2}
$$$$
v_{2}=1+0.083 v_{1}+0.875 v_{2} \text {. }
$$

Since a downturn necessarily starts in $i=1, v_{1}$ is the expected length of a downturn. 
Importantly, the higher delinquency is not due to the reform, since it would have been higher without it.

\subsection{Results}

Feeding the shock processes from Figures (7) into the model, we first simulate the labor market implications of the Great Recession. Figure (8) shows that the model closely matches the large rise in the duration of unemployment observed in the data, which transits from a pre-recession average of 1.5 quarters to a peak of 2.8 quarters.

Figure (9) shows that we also do a reasonable job matching the employment rate; the discrepancies are partly due to the fact that we take the initial calibration to be that from Low, Meghir, and Pistaferri (2010), who are trying to match long-run averages and not the unemployment rate in 2004.

While we can alter the parameters to get this number exactly, the quantitative results of the model would not differ substantially from what we report here. We do generate a large decline in employment, although the decline in the model is somewhat smaller than that in the data.

\subsubsection{Aggregate Default}

Figures (10) and (11) are the key predictions from the model - the dynamics of default during the Great Recession. Looking first at bankruptcy, our model captures the spike in filings driven by the announcement of BAPCPA one period before enactment. We also get a reasonable match to the subsequent drop and recovery, although the model predicts a persistently higher-than-observed filing rate.

Turning to delinquency, our model matches the data reasonably well except for the large downward spike in debt in delinquency observed in the last quarter of 2005, coincident with the spike in filings. Mechanically, our model must produce such a spike, since households who have been holding delinquent debt suddenly discharge it through bankruptcy. We suspect that the absence of this spike in the data reflects a discrepancy with how delinquent debt is measured in the data, as it is likely that most if not all of the debt eliminated during the surge in bankruptcy filings was at least 90 days in arrears but had already been written off by lenders. To isolate the role of bankruptcy reform, we plot in each figure a third series, giving outcomes for bankruptcy and delinquency in the "no-reform" case. By contrasting this case with the outcomes under the reform case, we see that the model suggests that BAPCPA reduced bankruptcy filings substantially during the Great Recession. This is a main result of our analysis. Over the Great Recession, therefore, the model implied we would have observed a much larger level of filings in the absence of the reform. Moreover, that level is implied to remain high, rather than to return to the pre-reform levels we currently observe.

The model implies that, first, the reform likely suppressed bankruptcy rates substantially. In sharp contrast, delinquency was almost completely unaffected by the reform. In other words, while BAPCPA did reduce bankruptcies, it did not encourage more informal defaults significantly. To better understand the path of delinquency Figure 12 shows how the density of outcomes for the face value of debt for a borrower who enters delinquency changes with the labor market. The main 
effect of the reform was to shift rightward the distribution of these values: delinquency became a worse deal for borrowers immediately upon announcement of BAPCPA. However, once labor market conditions began to deteriorate in 2008 and 2009, we see that the density shifts back nearly to its original place. In other words, the growth of the set of borrowers who expected low future income dominated the ability of lenders to drive households to less generous debt forgiveness in delinquency. Absent the reform, delinquency rates would have risen given labor market outcomes.

The labor market changes that motivate our investigation are represented as coming from changes in both job-finding and job-separation rates. It is important, therefore, to gauge the relative importance of these two aspects of labor market risk. We do this next, in the simplest manner possible. Figures (13) and (14) show the effect of shutting down, one at a time, the shocks to job-finding rates, and then to separation rates, as represented by $\left(\lambda^{E}, \lambda^{N}\right)$. It is immediately clear from the figures that movements in job-finding rates matter by far the most. When we shut down changes to the job-finding rate and thereby let only job-separation rates vary, we see from the line labeled "Benchmark w/ constant job-finding rate" that default rates would have remained almost perfectly flat over the period of the Great Recession. Relatedly, without the Great Recession's large decline in job finding, our model says that bankruptcy reform would have been successful at reducing not only bankruptcy rates but default rates overall, and would have done so permanently. This finding is consistent with the implications of Chatterjee et al. 2007, who also study the BAPCPA reform and conclude that it would have reduced default, though it should be noted that their model is focused on formal, rather than informal, default, as is that of Gordon 2013. Conversely, consider next the implications of shutting off the shocks to separation, $\delta$, alone while allowing the shocks to job-finding to evolve as in the benchmark model. This is given by the line "Benchmark w/ constant separation rate" We see that this results in predictions for default and delinquency that are very similar to those in the benchmark. Fluctuations in separation rates do not appear to matter for default dynamics over the Great Recession.

\subsubsection{Deleveraging in the Great Recession}

At the outset, we noted that the recent recession was associated with the first sustained drop in the absolute level of aggregate unsecured debt holdings in US history (at least since the time series has been recorded). Aside from mortgage debt, it is this form of debt that experienced a dramatic fall of roughly 15\%. By contrast, other forms of debt, such as installment credit, remained flat, while student loan debt grew very substantially. Unsecured credit has a special role to play given its availability to those lacking collateral to obtain cheap financing. It is also the main form of credit for younger households, and appears to be an important instrument for smoothing unemploymentrelated shocks (Sullivan 2006, Herkenhoff 2012). The fact that the use of this form of credit declined so sharply at a time when the consumption smoothing needs of millions of households rose, and when many had lost substantial capacity to borrow against their owner-occupied homes (via home equity loans), is noteworthy for its implications for consumption smoothing and welfare. So we now address the question of what role BAPCPA and labor market conditions played in determining the terms and use of unsecured debt, with a focus on the extent to which we can account for the overall decline in its use, and the resulting fall in aggregate consumption.

Figure 15 plots the model's implications for aggregate debt relative to income. Two points 
are immediate: the model implies substantially more borrowing initially, during the boom, and a sharper fall in debt to income in the recession. Notice that part of the increase in borrowing before the recession is due to the reform: in the simulation without reform, the debt-to-income increases by 30 percent instead of 55 percent. The drop in borrowing is similar in both cases, however.

The reason for the likely greater sensitivity of the model to overall conditions is clearly seen in Figure 16. ${ }^{6}$ This figure shows the terms available to the median borrower (i.e. borrowers with median values for both match quality and individual productivity). The bankruptcy reform exerts a powerful influence on the cost of borrowing, which increases debt at the outset (between 2005 and 2008). As soon as labor market conditions deteriorate, however, we see that credit contracts (see bottom panel of Figure 16), which then leads to a sharp reduction in borrowing and a sharp increase in default. The top panel of Figure 16 shows how households respond; in this case, we see that in 2009, for almost all debt levels there is either a sharp deleveraging for high debt levels, or maintenance of the entering debt level for low levels. There is essentially no leveraging taking place for the relatively young household with the median constellation of wage shocks. In contrast, in 2006 agents with substantially more debt maintained or increased their debt. A good deal of this behavior is coming from the worsened terms prevailing in 2009. The dashed red line in the top panel of Figure 16 shows that if households were to face 2009 labor market conditions with 2006 prices, they would indeed borrow more.

Figure 17 shows that the same patterns hold for the worst off (low $m$, low $n$ ), who are represented relatively heavily among the borrowing population and for whom borrowing costs rise very substantially (bottom panel) as the recession occurs.

Figure 18 shows how labor market status and deleveraging are connected. In the top panel, we see that desired debt levels plummet for those who have experienced a job separation-the poor prospects for future earnings imply, for these agents, a drop in debt of nearly 50 percent! Next, notice the role of pricing in this: the dashed red line shows that 2009 conditions would generate substantial leveraging, not deleveraging. The bottom panel provides the explanation: loan prices plummet (interest rates rise sharply). Our model suggests that a substantial proportion of households were severely credit constrained, and that this tightening had much to do with aggregate deleveraging; the credit market tightened at precisely the moment that many households would have liked to borrow more. ${ }^{7}$ We stress, however, that the model is prone to overemphasizing the fall in debt because most households are savers and not borrowers.

Finally, Figure 19 shows the dynamics of aggregate consumption over the Great Recession. The model's predicted decline in consumption relative to trend is fairly close to that observed in the data. The reform is not apparent at the level of aggregate consumption, while labor market risk does seem powerful in reducing aggregate consumption. The mechanism by which this occurs is twofold. First, increased risk generates increased precautionary savings motives for all agents, especially anyone doing temporarily well in terms of the labor market outcomes. Second, in essentially all

\footnotetext{
${ }^{6}$ Ausubel (1991) shows the imperfect competition in credit card lending could deliver interest rates that are insensitive to current conditions, which would mute the sensitivity of debt in the model. The observed decline in the risk-free rate would also contribute to reducing the size of the drop in debt.

${ }^{7}$ Athreya, Tam, and Young (2009) note that this tightening is typical in debt markets that are short-term and feature symmetric information - the terms of credit react immediately to any deterioration in individual borrowers' economic conditions.
} 
models of the type we employ here - where loan pricing is required to break even period-by-periodthe interest rate on borrowing is sensitive to individual-level circumstances. In our context, this feature leads to the terms of credit tightening substantially early in the Great Recession and then loosening again as the labor market improves. As a result, credit use falls as "deleveraging" is partially enforced by the credit market early on in the downturn, something that then works in reverse as employment risk falls.

\section{Conclusions}

We have assessed the role of bankruptcy reform and labor market shocks at generating the significant dynamics exhibited by bankruptcy, delinquency, and unsecured debt during the Great Recession. In doing so, we have provided, to our knowledge, the first quantitative evaluation of the transitional dynamics induced by bankruptcy reform of 2005 and, especially, its impact on outcomes during the period of the Great Recession. Our two central findings are as follows. First, in the short run (i.e., during the Great Recession), the reform did lead to substantially less bankruptcy, given the shocks to aggregate job finding and separation rates, but it did not generate substantial increases in delinquency, nor did it change the time path of aggregate debt. Second, we find that declines in hiring rates are by far the more important labor market shock.

We have maintained a narrow focus on unsecured credit markets and labor markets, but it is clearly of interest to extend our model to incorporate additional changes observed during the Great Recession, such as negative real interest rates and fluctuations in the distribution of wages. As for the latter in particular, Guvenen, Ozkar, and Song (2013) document that there is countercyclical variation in the skewness of labor income during recessions, which clearly would affect how agents make default decisions. We could also endogenize the job-finding rates to capture feedback from credit markets to labor markets, perhaps by augmenting the model to include two-sided matching. We leave these extensions to future work. Lastly, the fact that our model is not only consistent with steady state facts but also with dynamic ones gives us more confidence in its ability to assess alternative policies, such as the welfare effects of garnishment (studied in Athreya et al. 2013) or the consequences of usury laws and other interest rate ceilings. 


\section{References}

[1] Athreya, K., Sánchez J.M., Tam, X.S., and Young, E.R., (2012). "Bankruptcy and delinquency in a model of unsecured debt," Working Paper 2012-42A, Federal Reserve Bank of St. Louis.

[2] Athreya. K., Tam, X.S., and Young, E.R. (2009). "Unsecured credit markets are not insurance markets," Journal of Monetary Economics 56(1), 83-103.

[3] Ausubel, L.M., (1991). "The failure of competition in the credit card market," American Economic Review 81(1), 50-81.

[4] Benjamin, D., and Mateos-Planas, X., (2012). "Formal vs. informal default in consumer credit," 2012 Meeting Papers 144, Society for Economic Dynamics.

[5] Chatterjee, S., Corbae, P.D., Nakajima, M., and Ríos-Rull, J.-V., (2007). "A quantitative theory of unsecured consumer credit with risk of default," Econometrica 75(6), 1525-1589.

[6] Chatterjee, S., and Gordon, G. (2012). "Dealing with consumer default: bankruptcy vs. garnishment," Journal of Monetary Economics 59(S), 1-16.

[7] Chen, D. (2013). "The impact of personal bankruptcy on labor supply decisions," manuscript, Florida State University.

[8] Eggertson, G.B., and Krugman, P., (2012). "Debt, deleveraging, and liquidity trap: a FisherMinsky-Koo approach," Quarterly Journal of Economics 127(3), 1469-1513.

[9] Evans, D.S., and Schmalensee, R., (1999). Paying with plastic: the digital revolution in buying and borrowing. MIT Press.

[10] Gordon, G., (2013). "Evaluating default policy: the business cycle matters," manuscript, Indiana University.

[11] Guerrieri V., and Lorenzoni, G., (2011). "Credit crises, precautionary savings, and the liquidity trap," NBER Working Paper 17583, National Bureau of Economic Research, Inc.

[12] Guvenen, F., Ozkar, S., and Song, J. (2013). "The nature of countercyclical income risk," NBER Working Paper 18035, National Bureau of Economic Research, Inc.

[13] Herkenhoff, K. (2012). "The role of default (not bankruptcy) as unemployment insurance: new facts and theory," manuscript, University of California - Los Angeles.

[14] Lawless, R.M., Littwin, A.K., Porter, K.M., Pottow, J.A.E., Thorne, D.K., and Warren, E. (2008). "Did bankruptcy reform fail? An empirical study of consumer debtors," American Bankruptcy Law Journal 82, 349-406.

[15] Low, H., Meghir, C., and Pistaferri, L., (2010). "Wage risk and employment risk over the life cycle," American Economic Review 100(4), 1432-67. 
[16] Mian, A., and Sufi, A., (2010). "Household leverage and the recession of 2007 to 2009," NBER Working Paper 15896, National Bureau of Economic Research, Inc.

[17] Morgan, D., (2012), "Is the 2005 bankruptcy reform working?" http://libertystreeteconomics.newyorkfed.org/2012/06/is-the-2005-bankruptcy-reformworking.html.

[18] Sullivan, J.X., "Borrowing during unemployment: unsecured debt as a safety net," Journal of Human Resources, 43(2), 383-412.

[19] Sullivan, T.A., Warren, E. and Westbrook, J.L., (2000). The fragile middle class: Americans in debt. Yale University Press.

[20] White, M.J., (1997), "Why don't more households file for bankruptcy?" Journal of Law, Economics, and Organization 14(2), 205-231.

[21] Wolff. E.N., (2006). "Changes in household wealth in the 1980s and 1990s in the United States," in Wolff, E.N. (ed.), International Perspectives on Household Wealth, Elgar Publishing, 107150 . 
Figure 1: Deleveraging

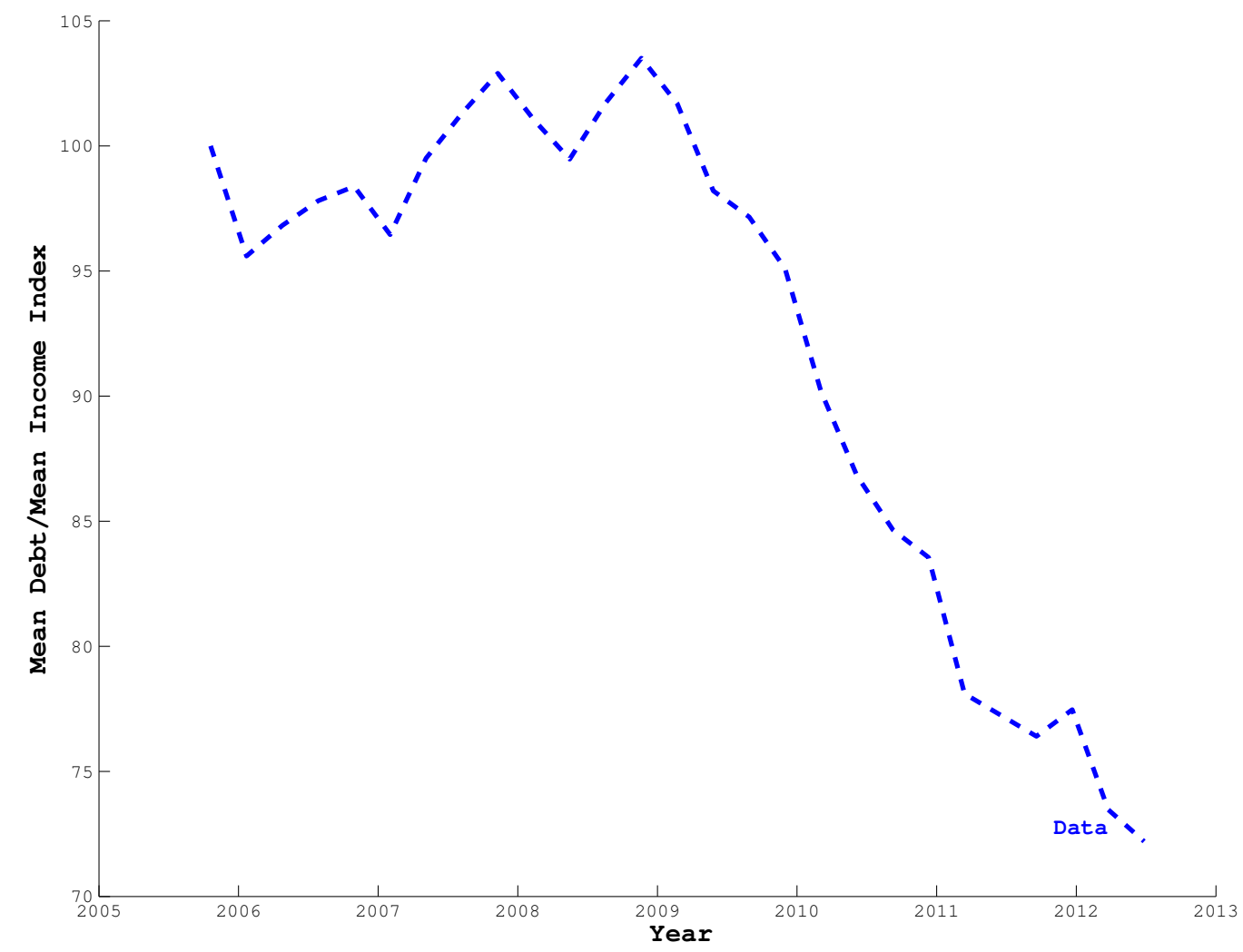


Figure 2: Labor Market Upheaval

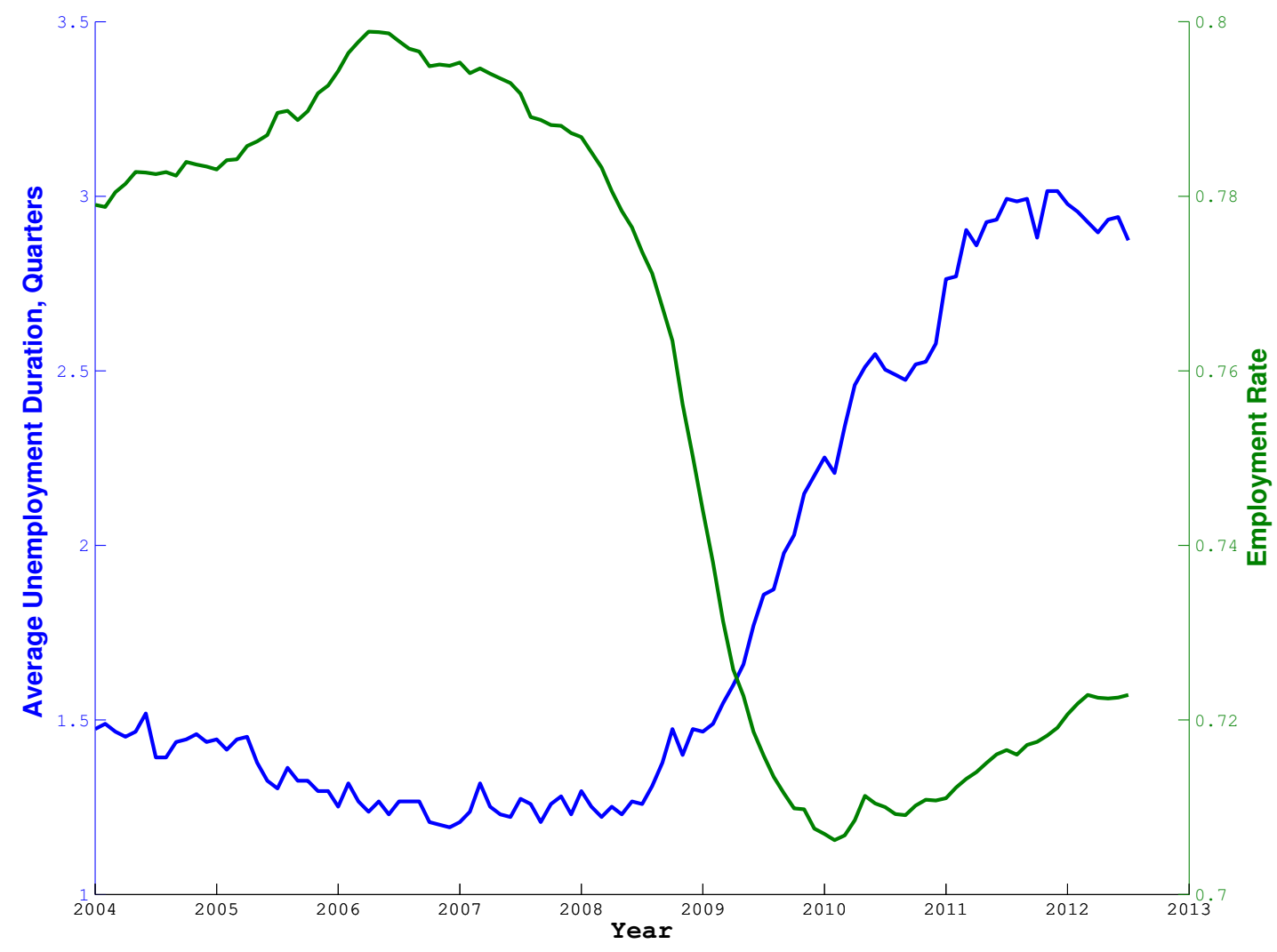


Figure 3: Defaults in Credit Market

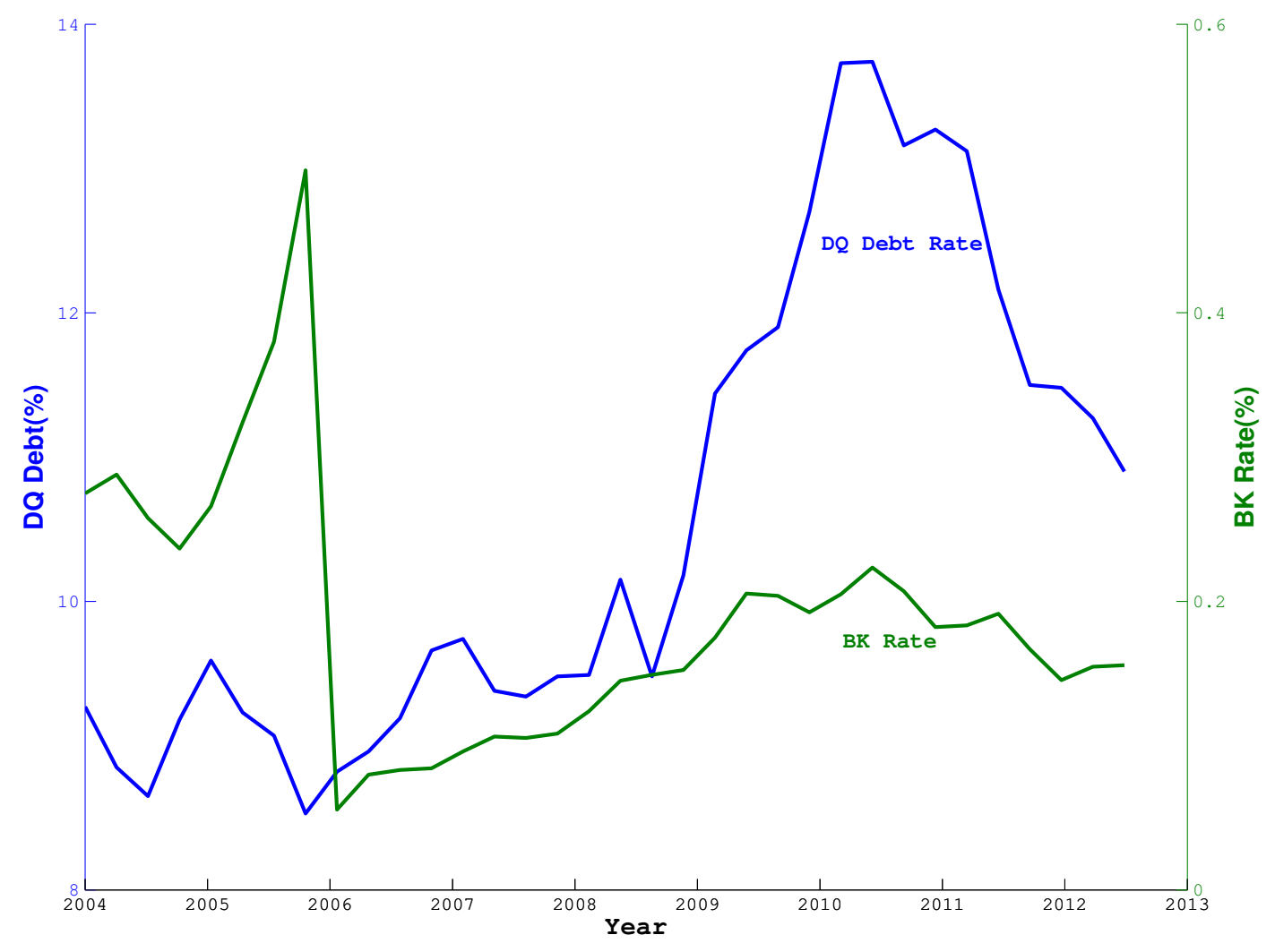


Figure 4: Understanding the decision between BK and DQ (high (left) and low (right) edu, age 33)
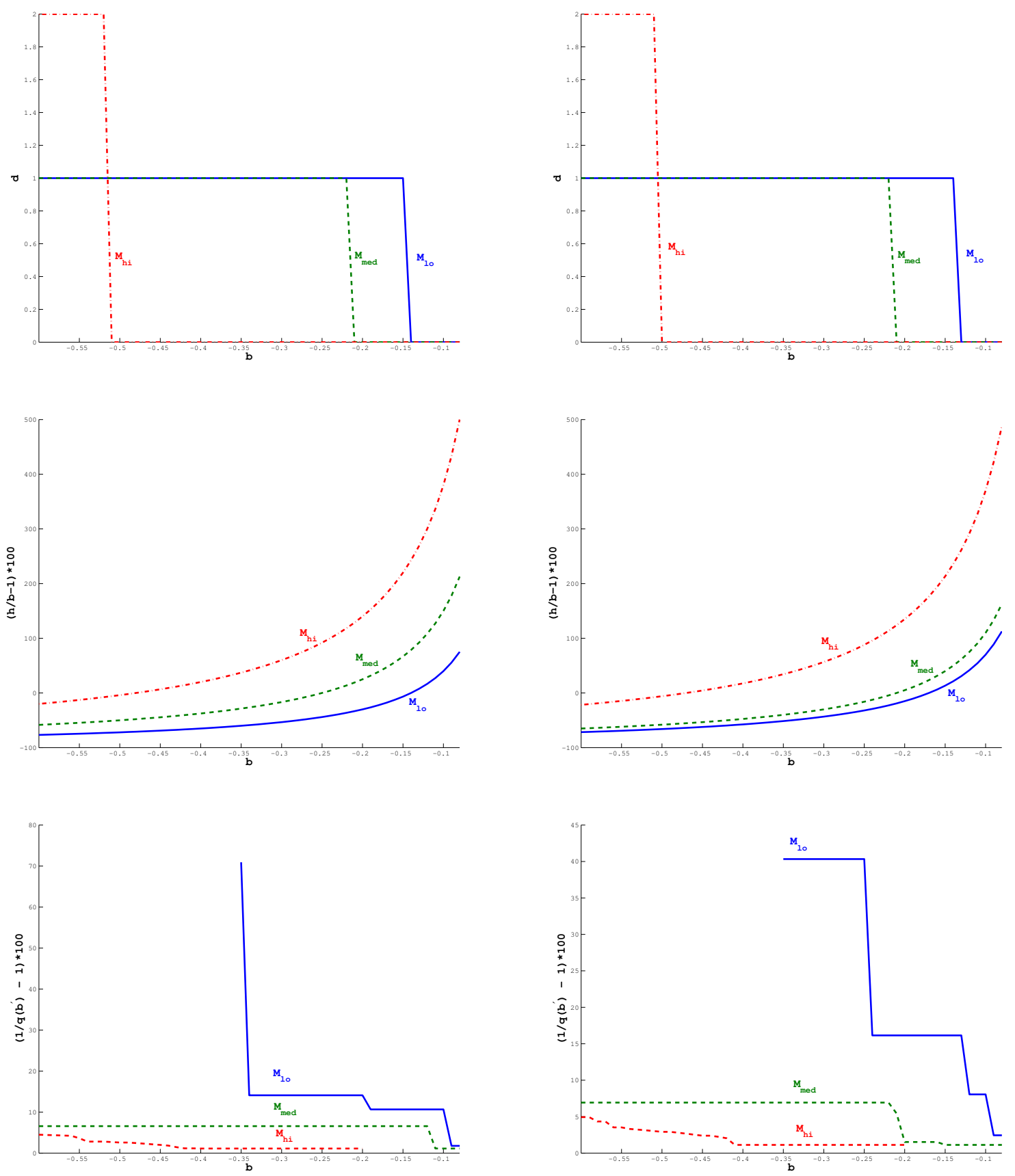
Figure 5: Understanding the decision between BK and DQ (high edu, age 33)
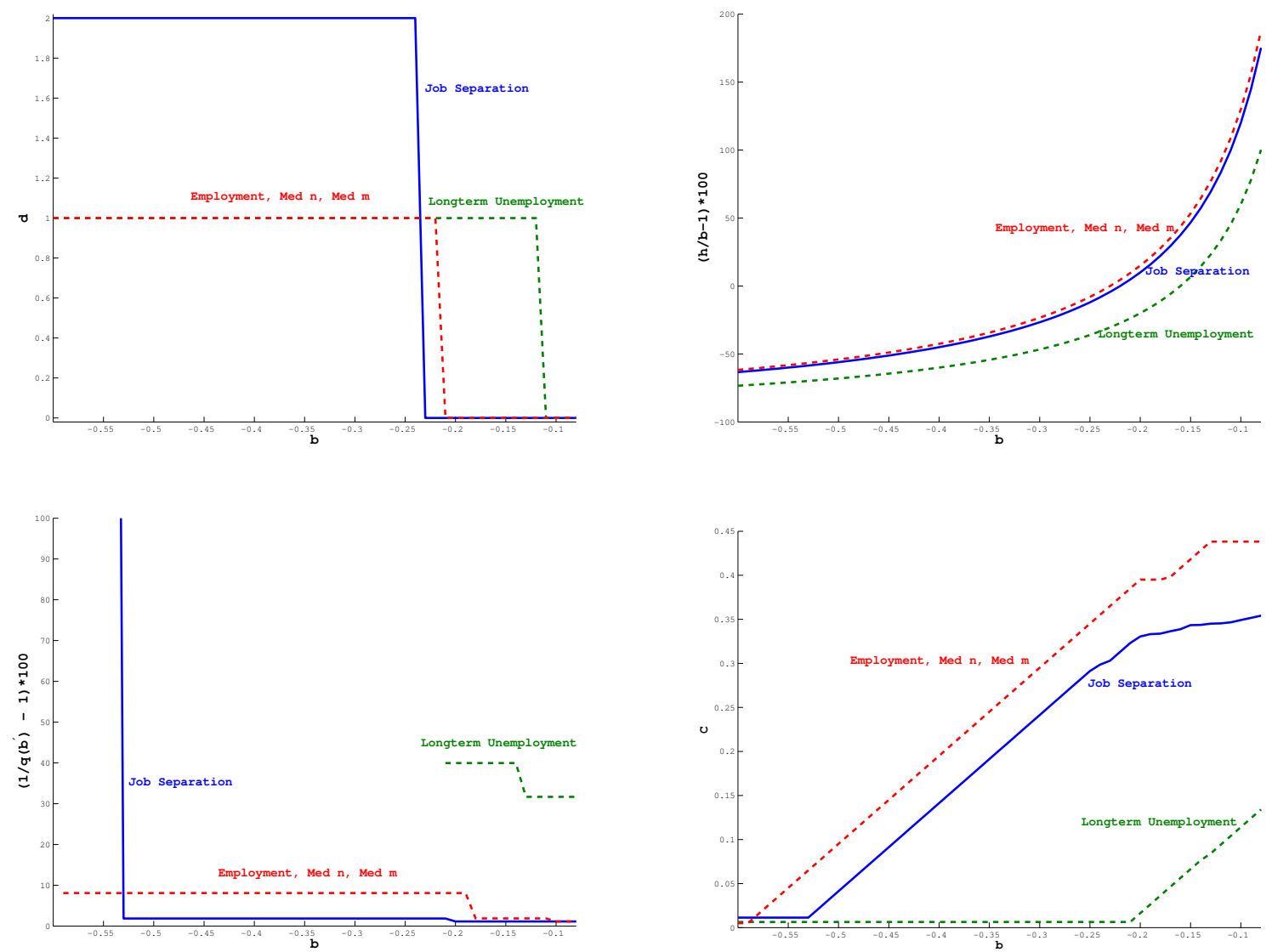
Figure 6: Timeline for Simulating the Great Recession

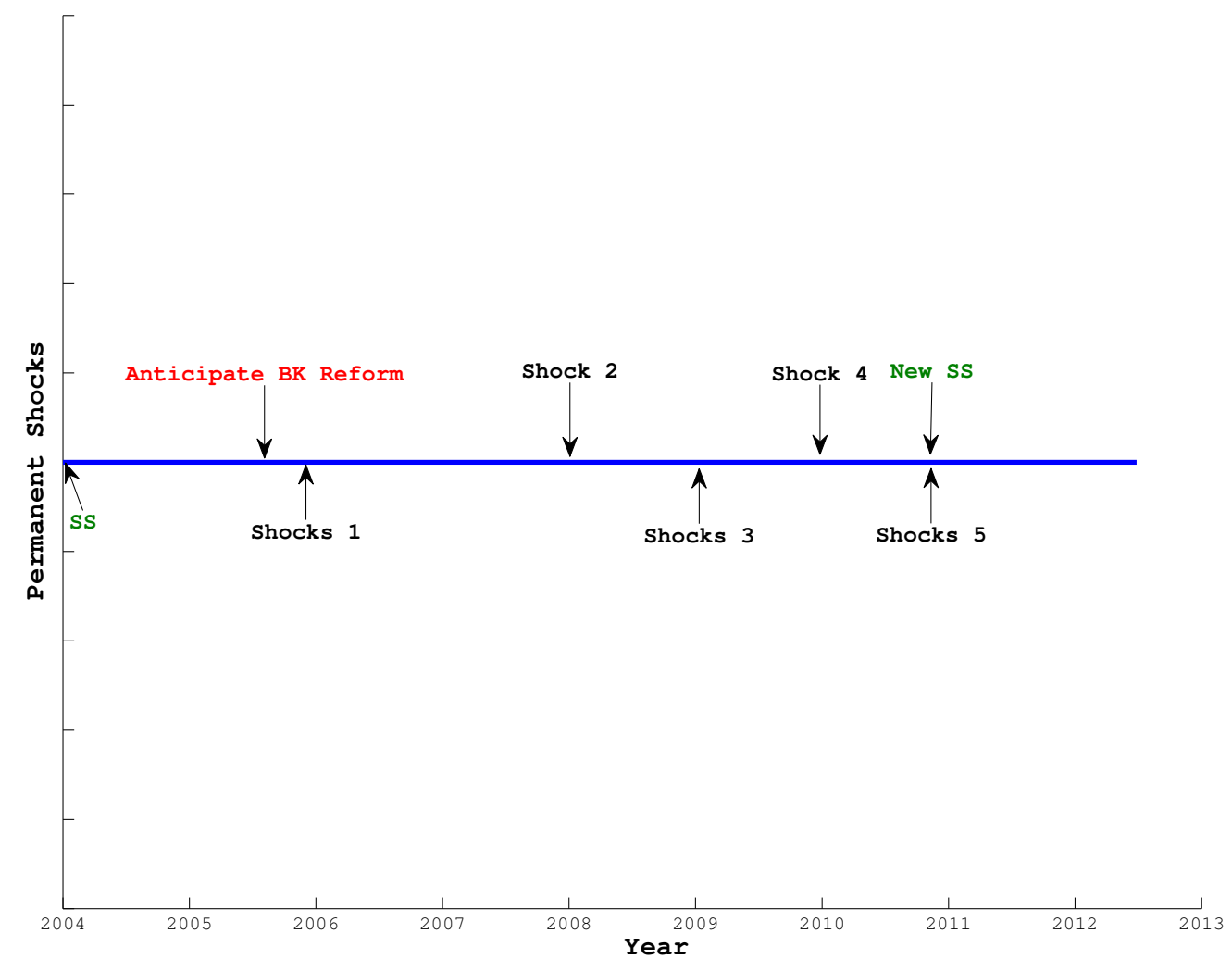


Figure 7: Shocks for High (top) and Low (bottom) Education Type
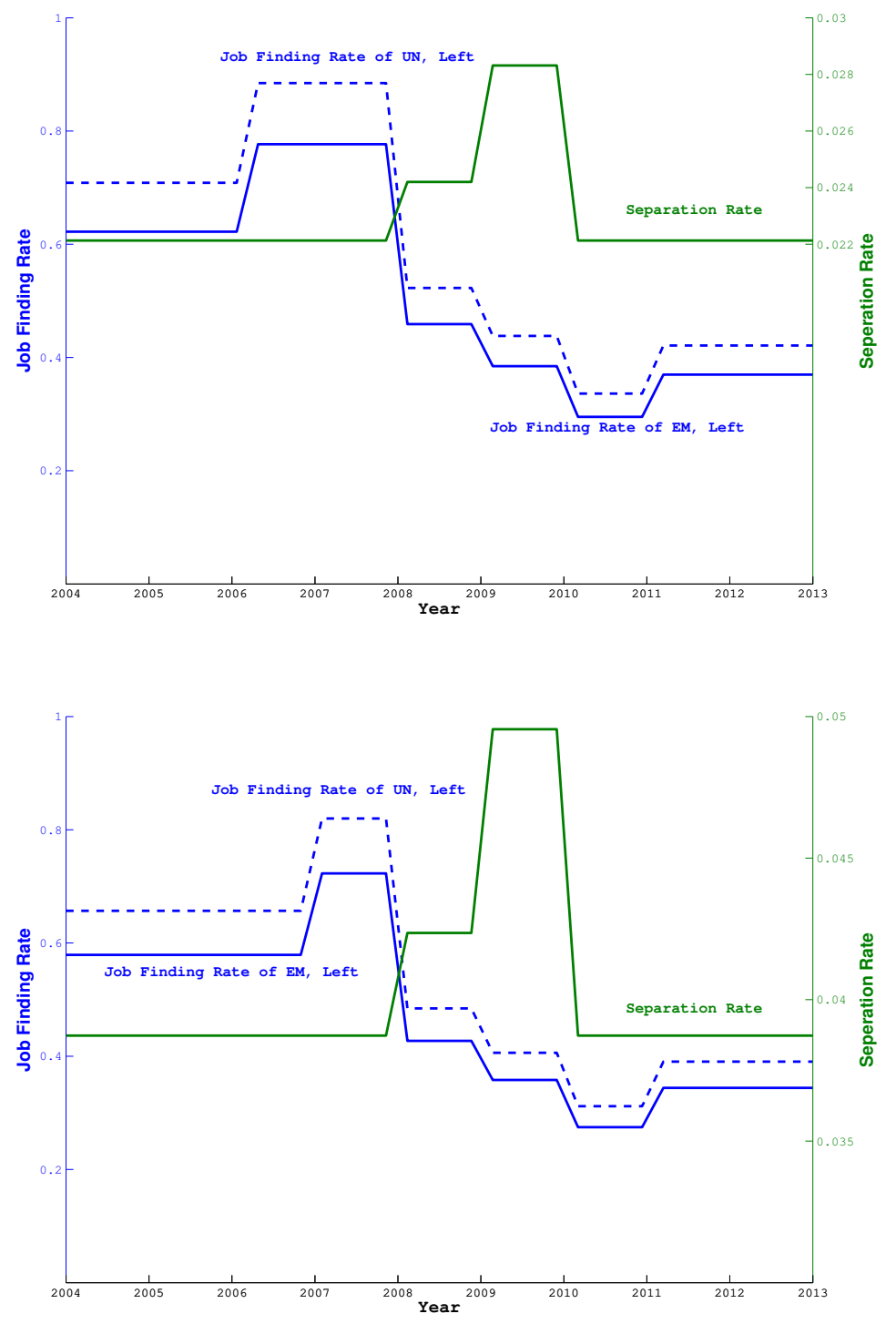
Figure 8: Average Unemployment Duration

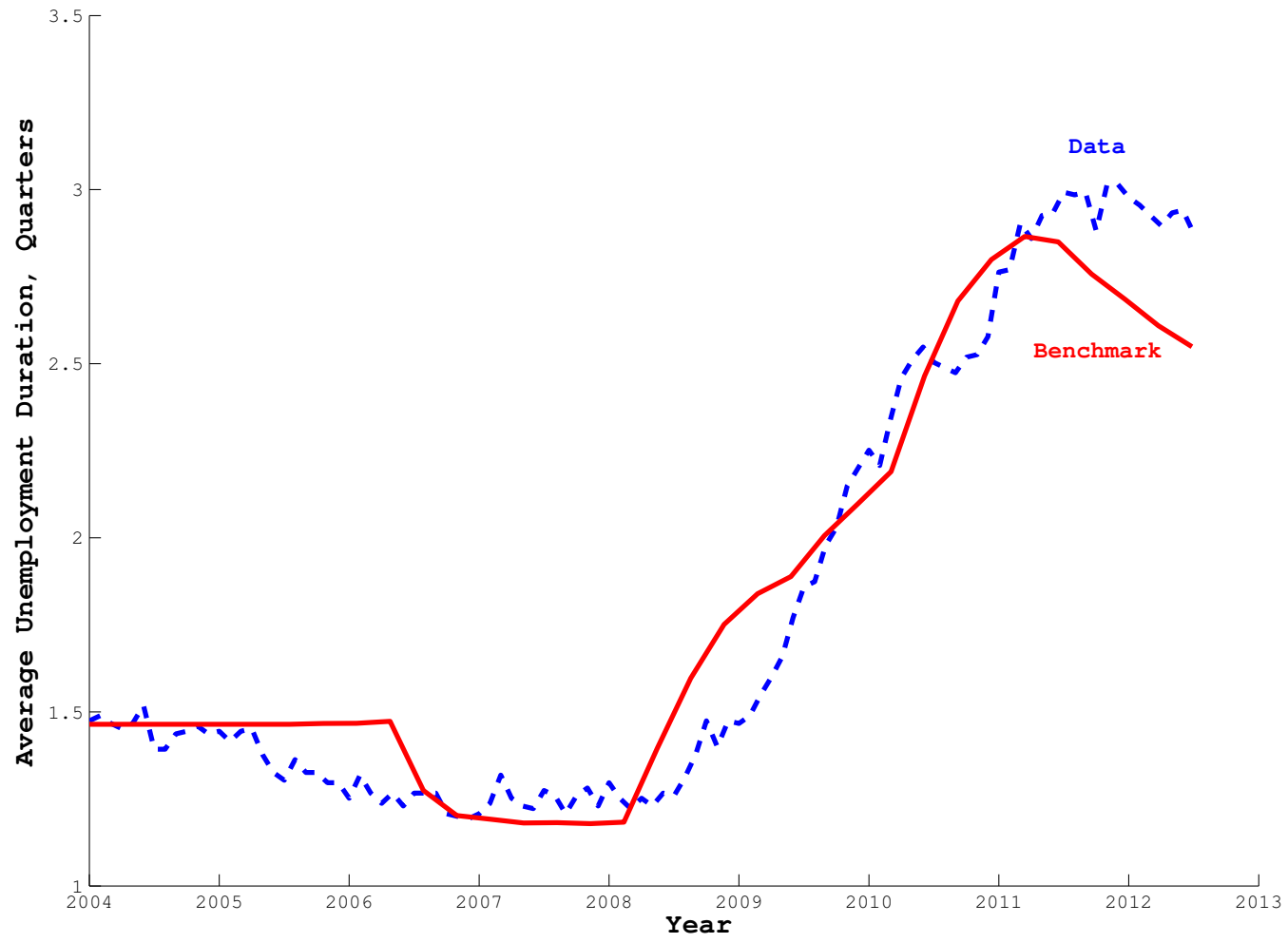


Figure 9: Employment Rate

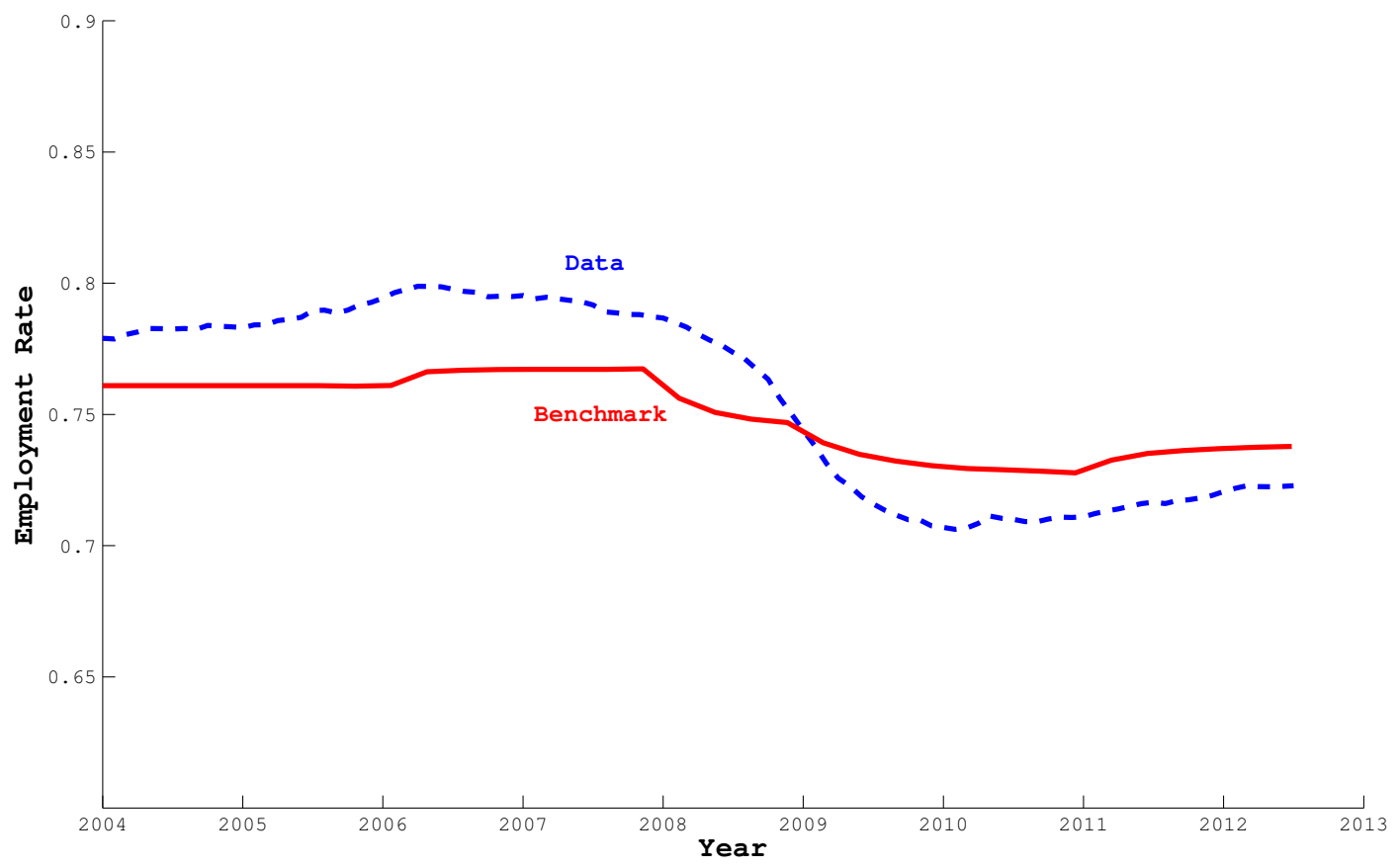


Figure 10: Percentage of Households Filing for Bankruptcy

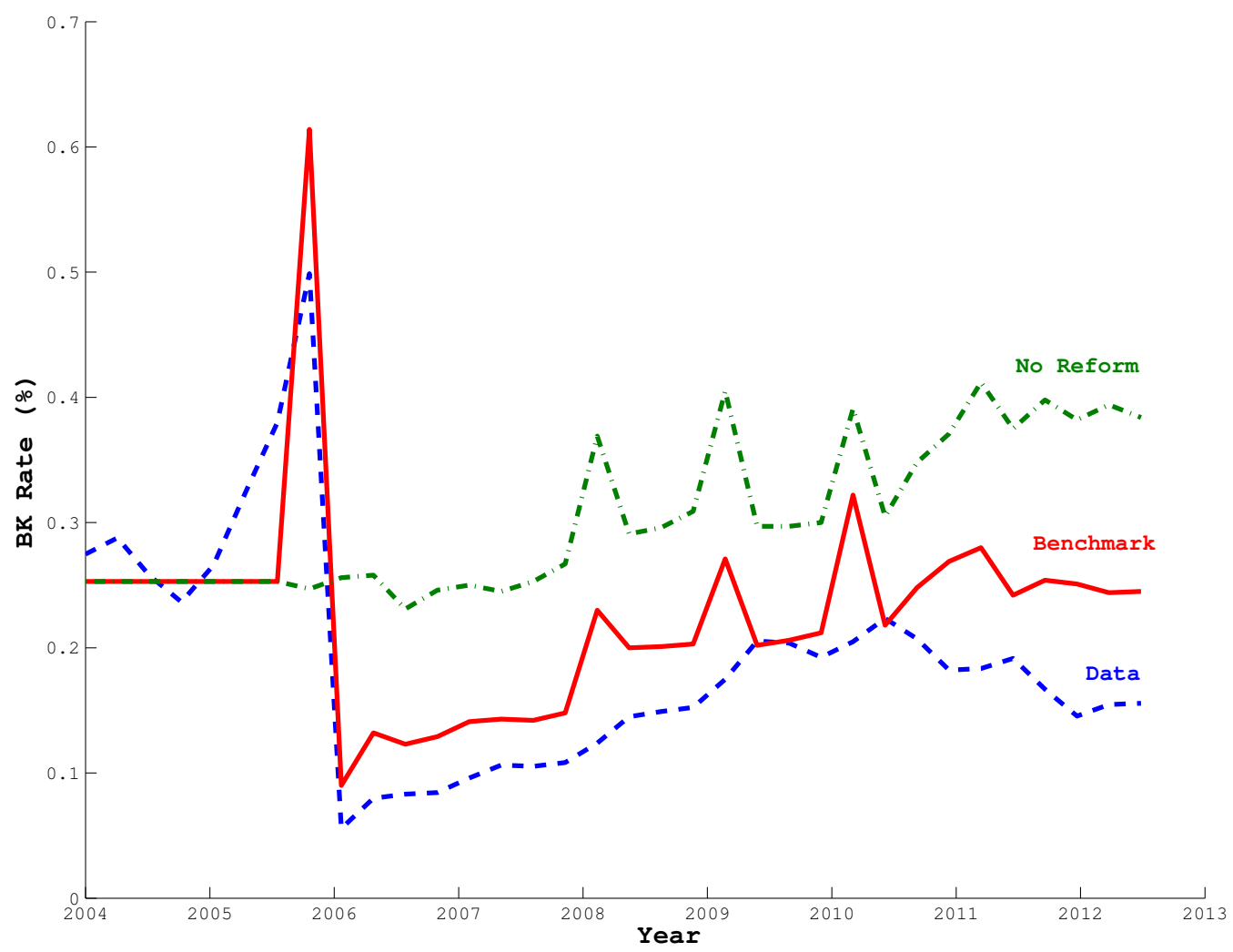


Figure 11: Percentage of Debt in Delinquency

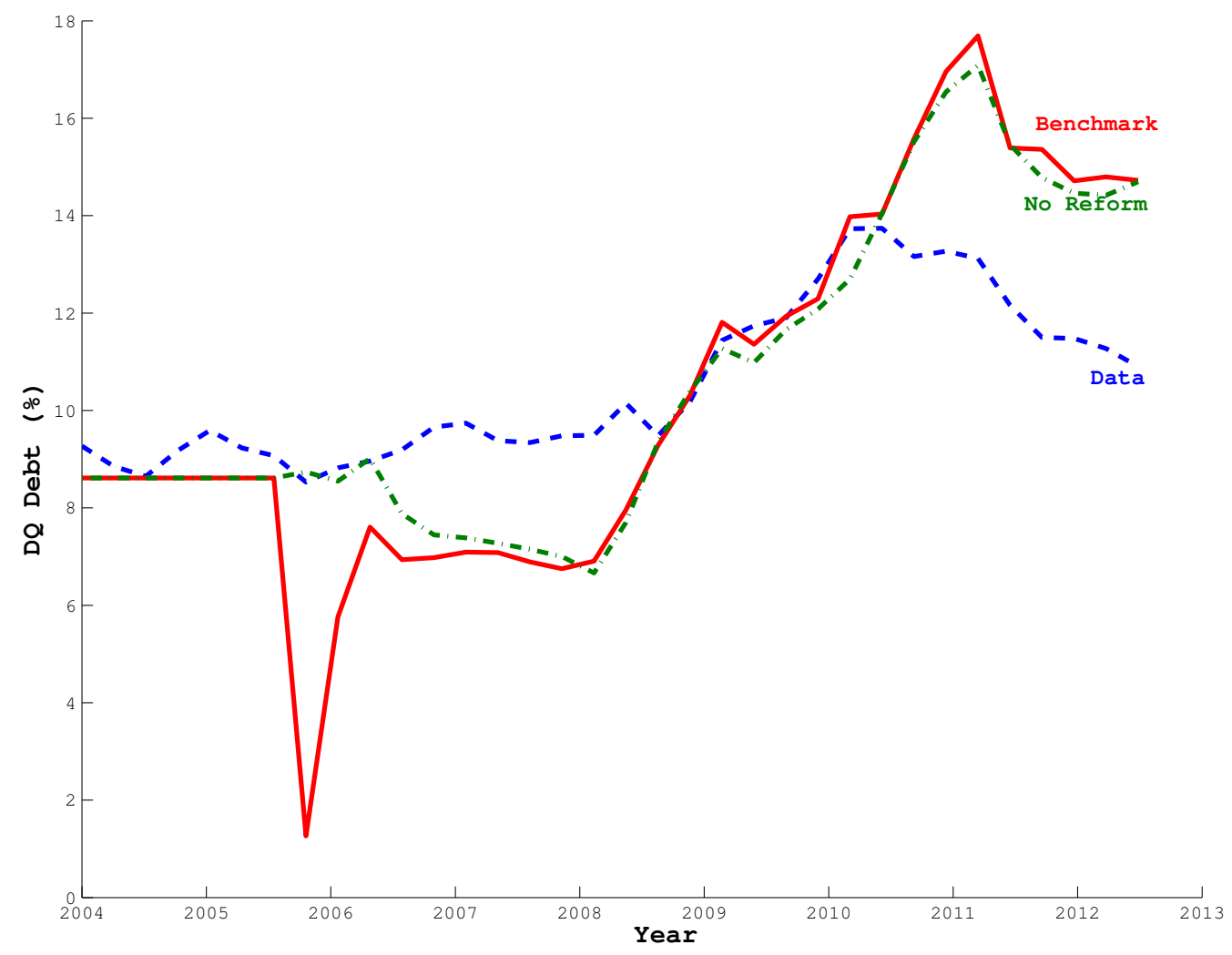


Figure 12: Density of the face value of debt for delinquent borrower

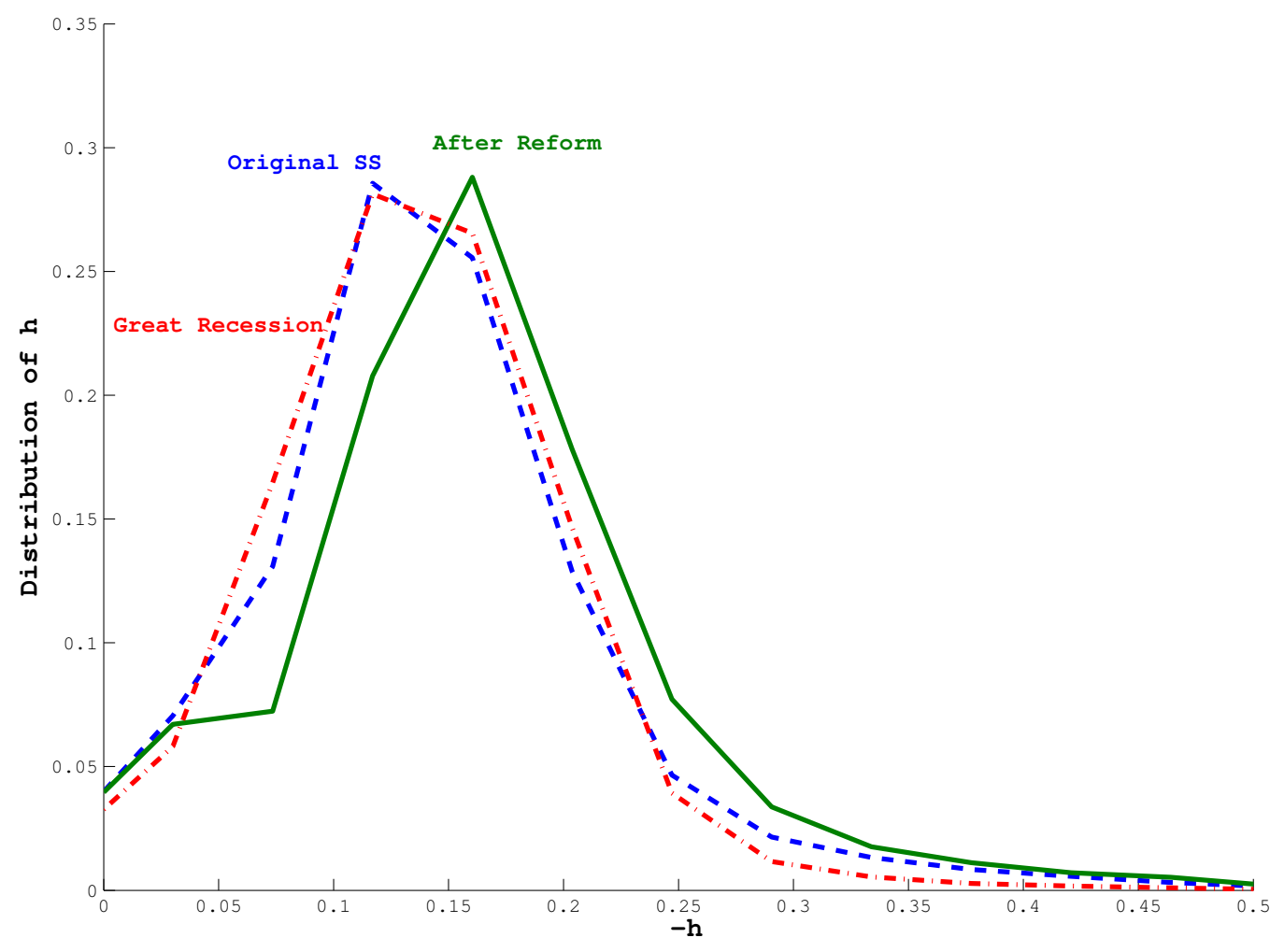


Figure 13: Percentage of Households Filing for Bankruptcy

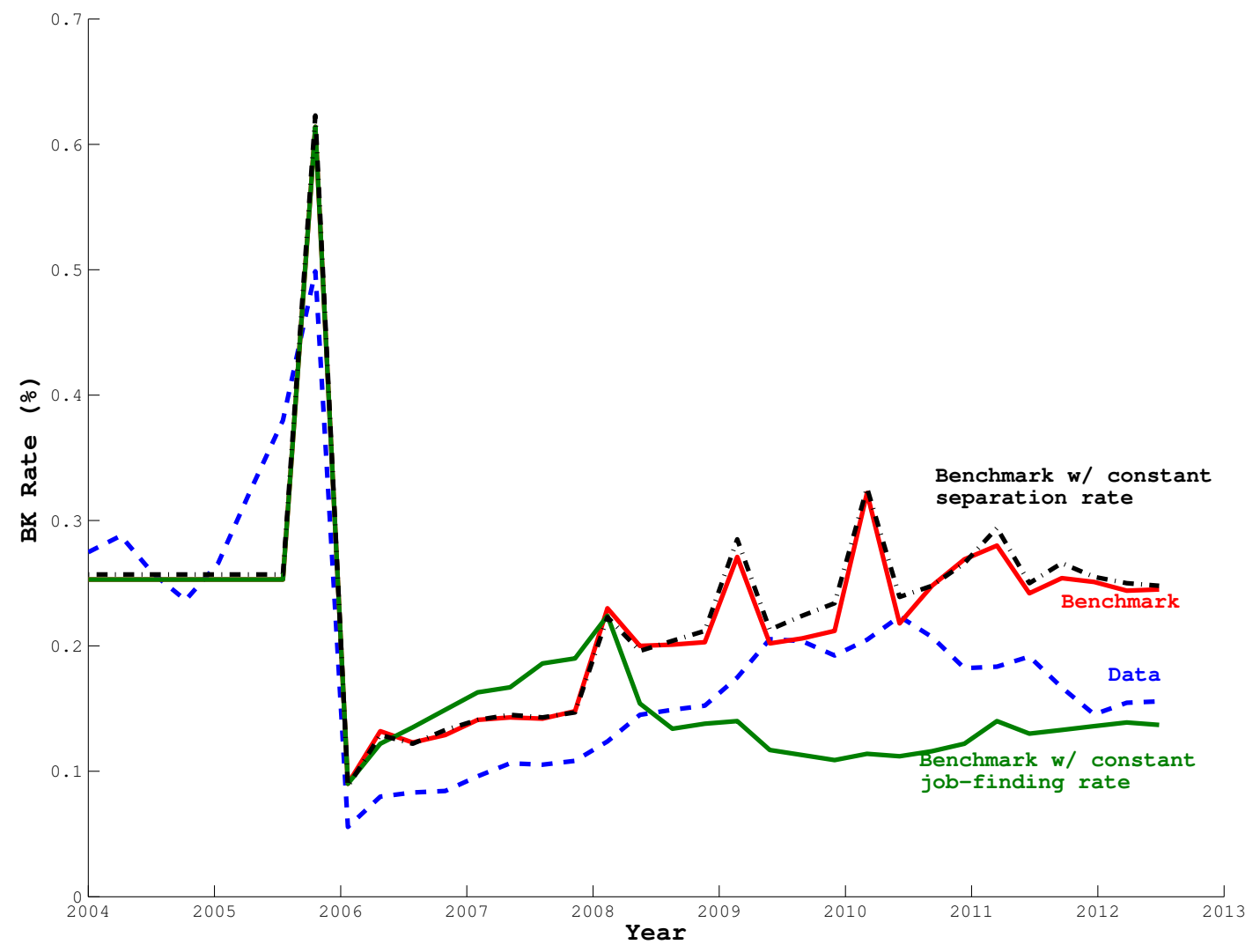


Figure 14: Percentage of Debt in Delinquency

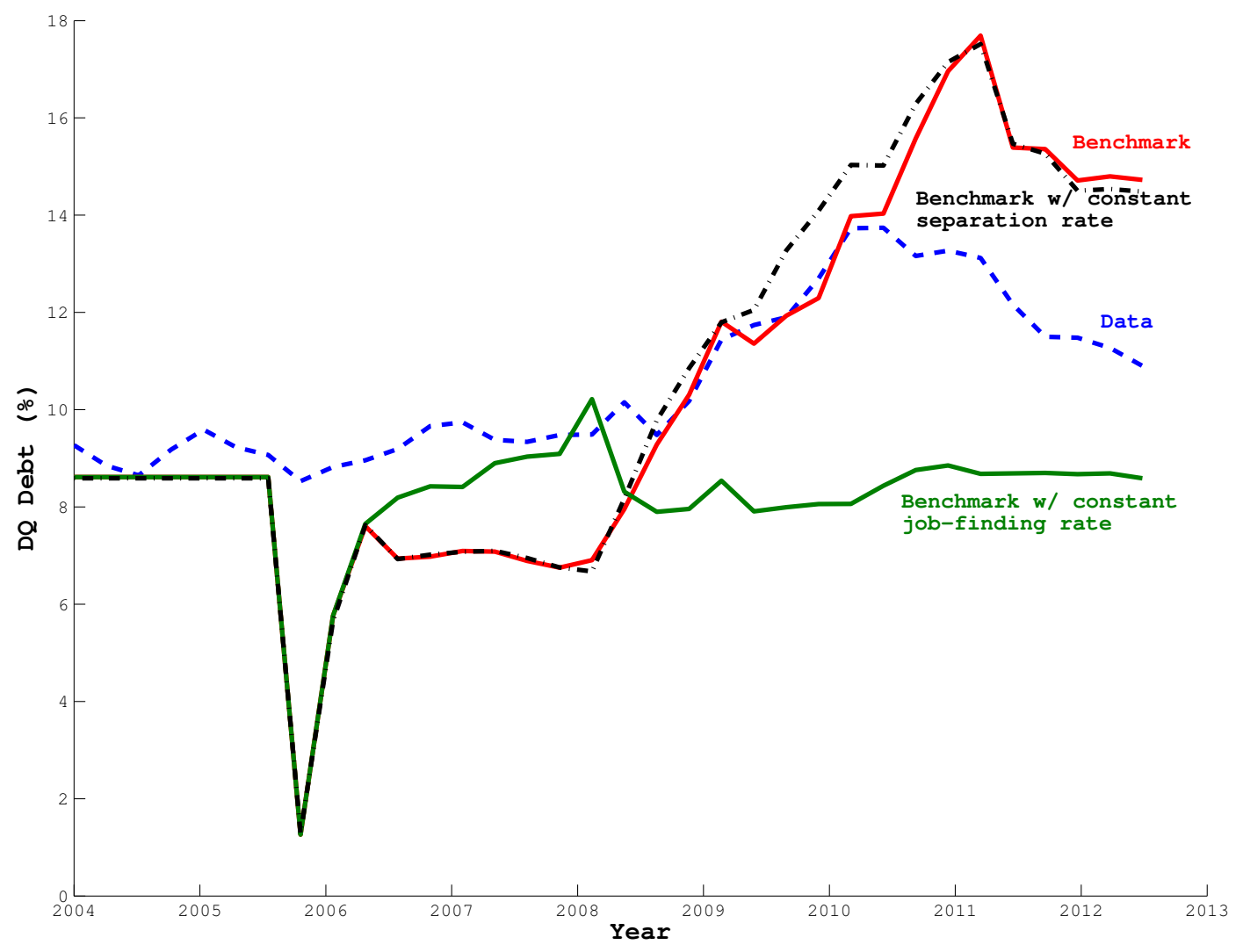




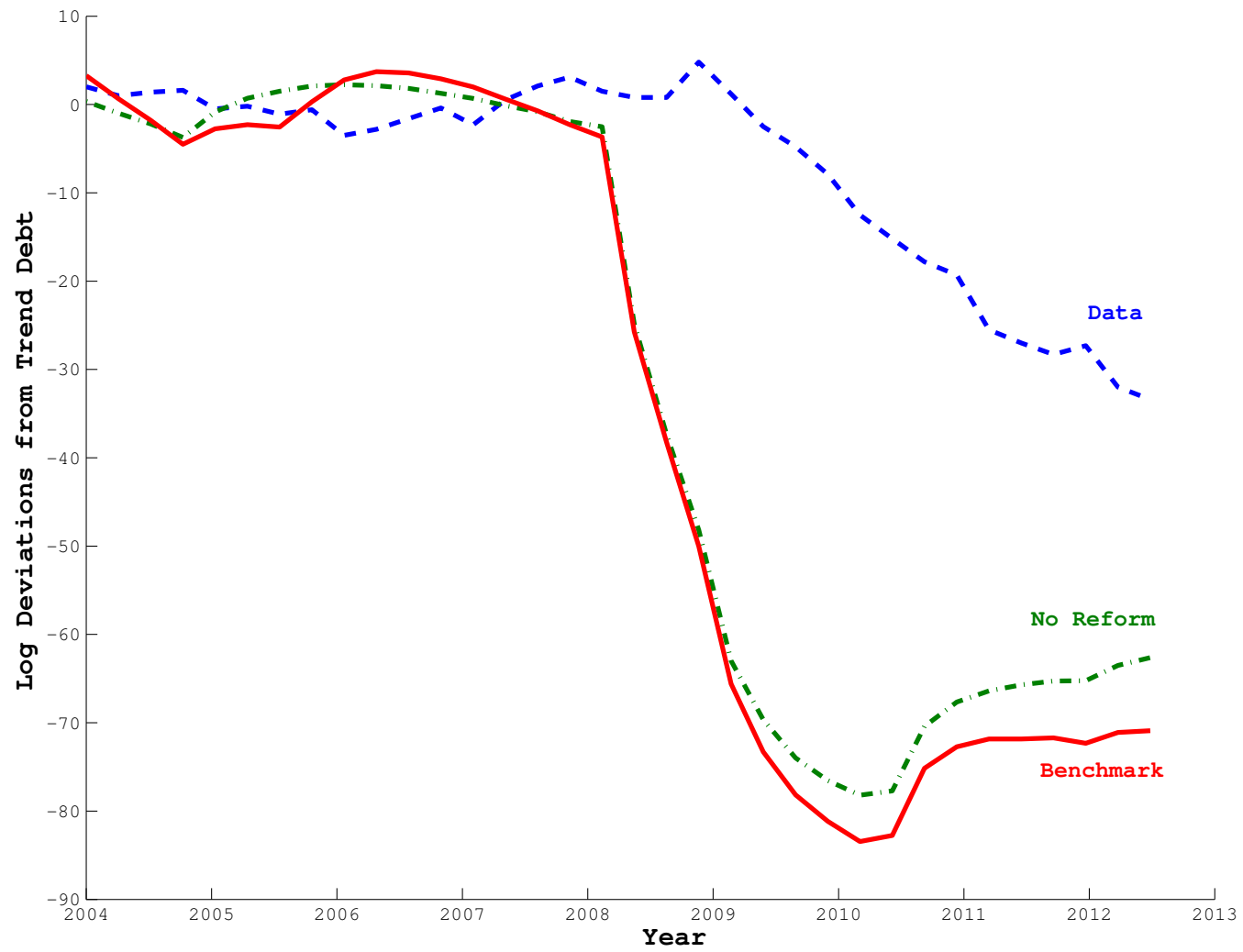

Figure 15: Aggregate Debt during the great recession 
Figure 16: Borrowing, policy functions (households with mid n, mid n, and age 33)
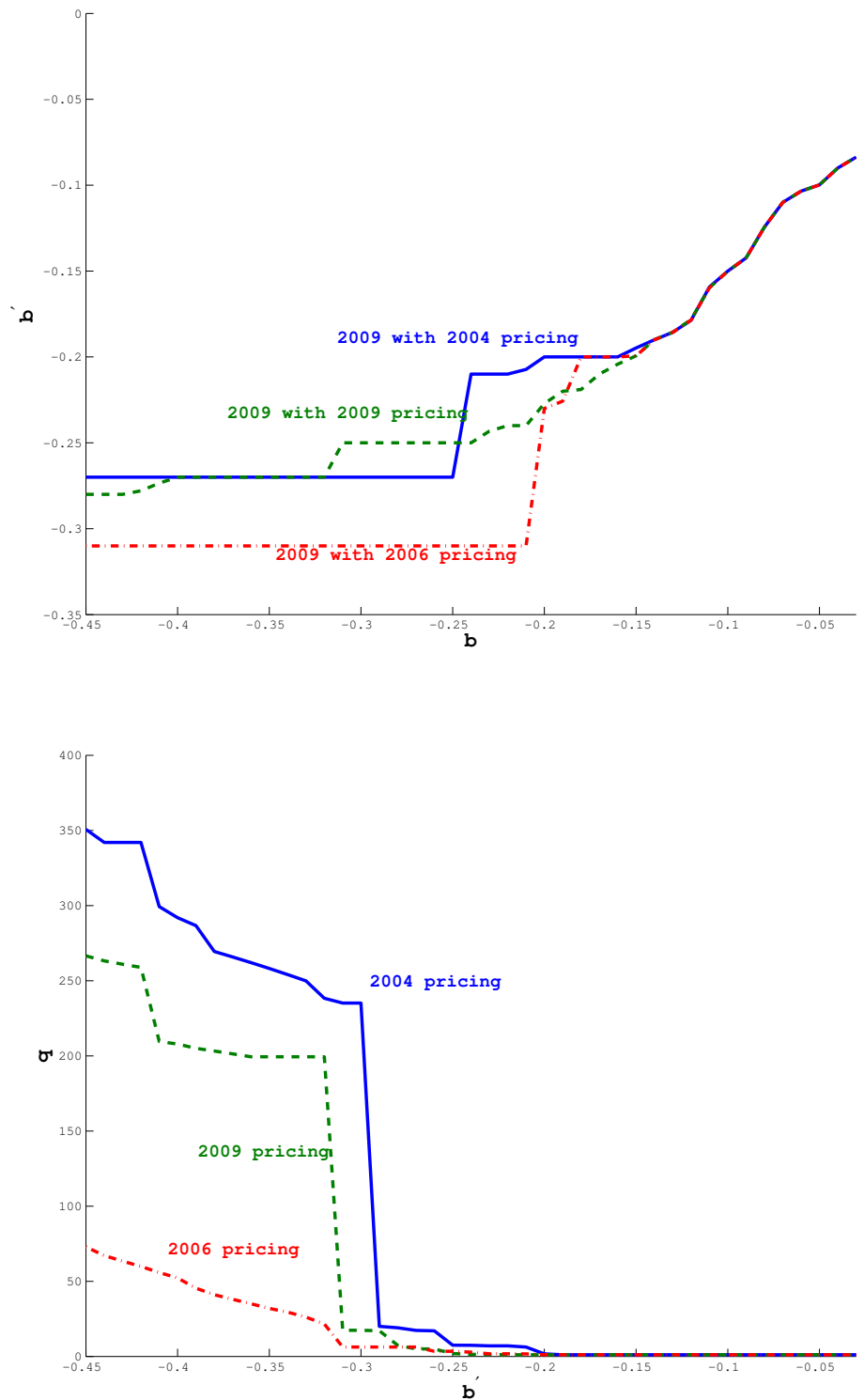
Figure 17: Borrowing, policy functions (households with low n, low n, and age 33)
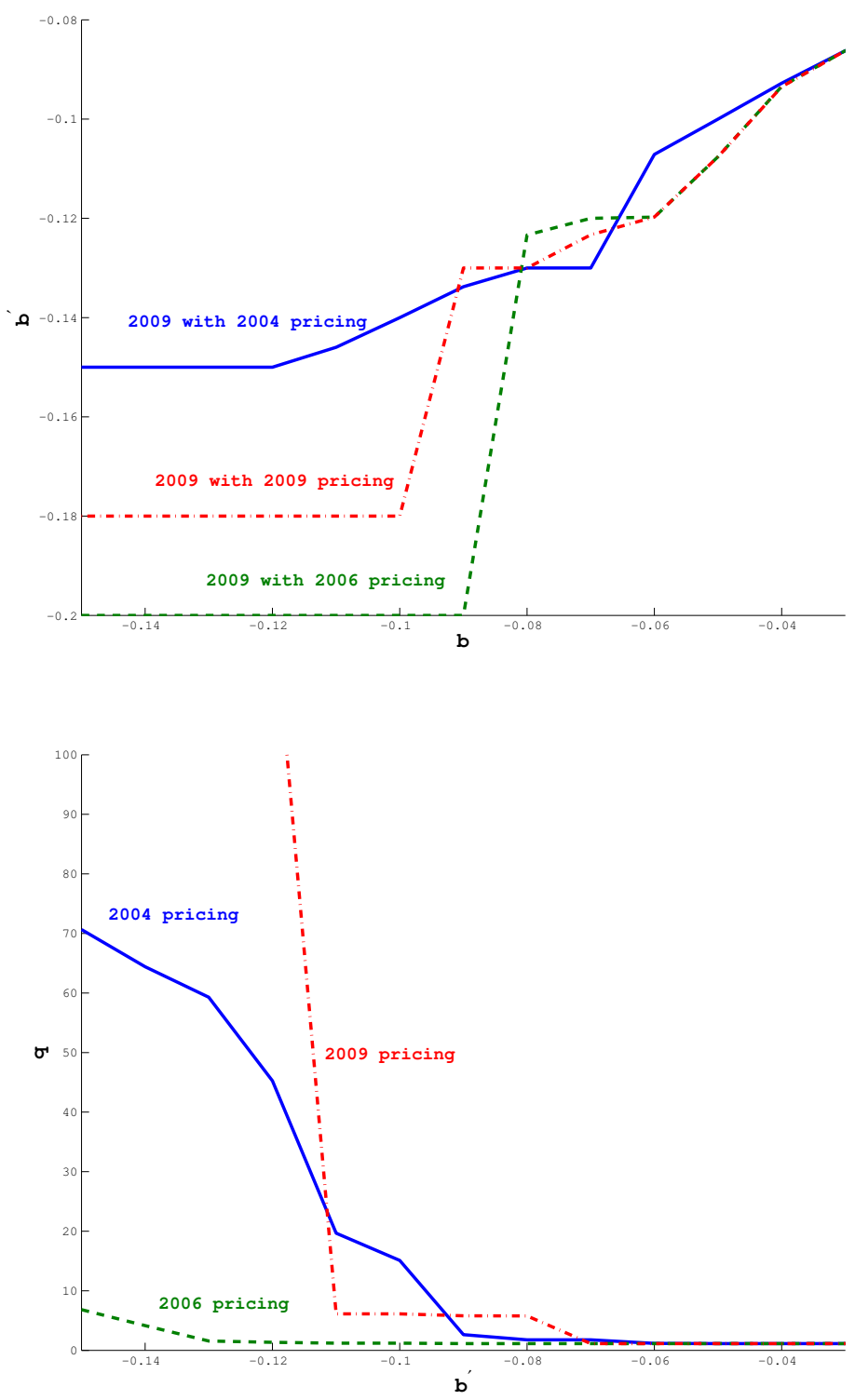
Figure 18: Borrowing, policy functions (high n, short-term unemployed, age 33)
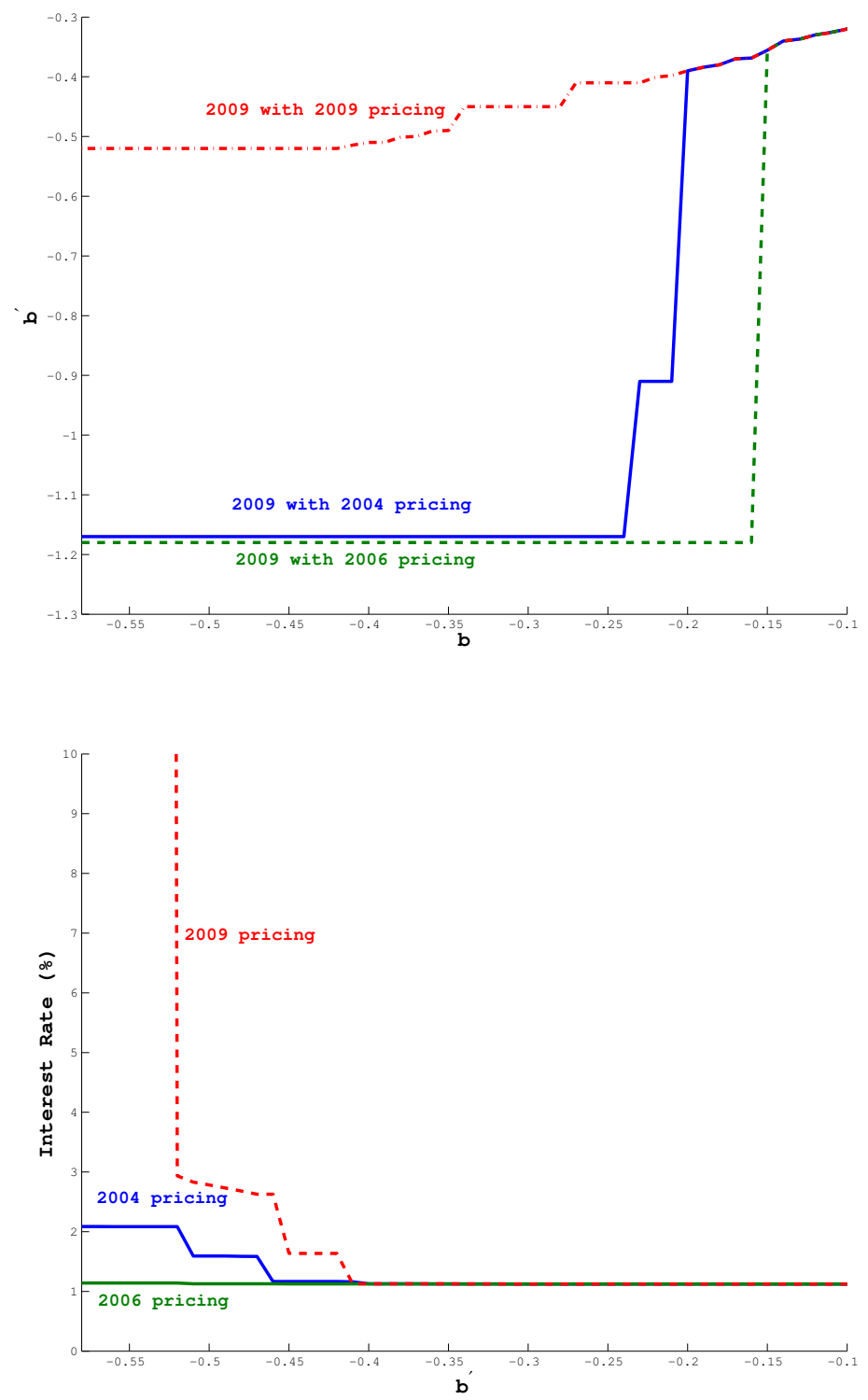
Figure 19: Aggregate Consumption

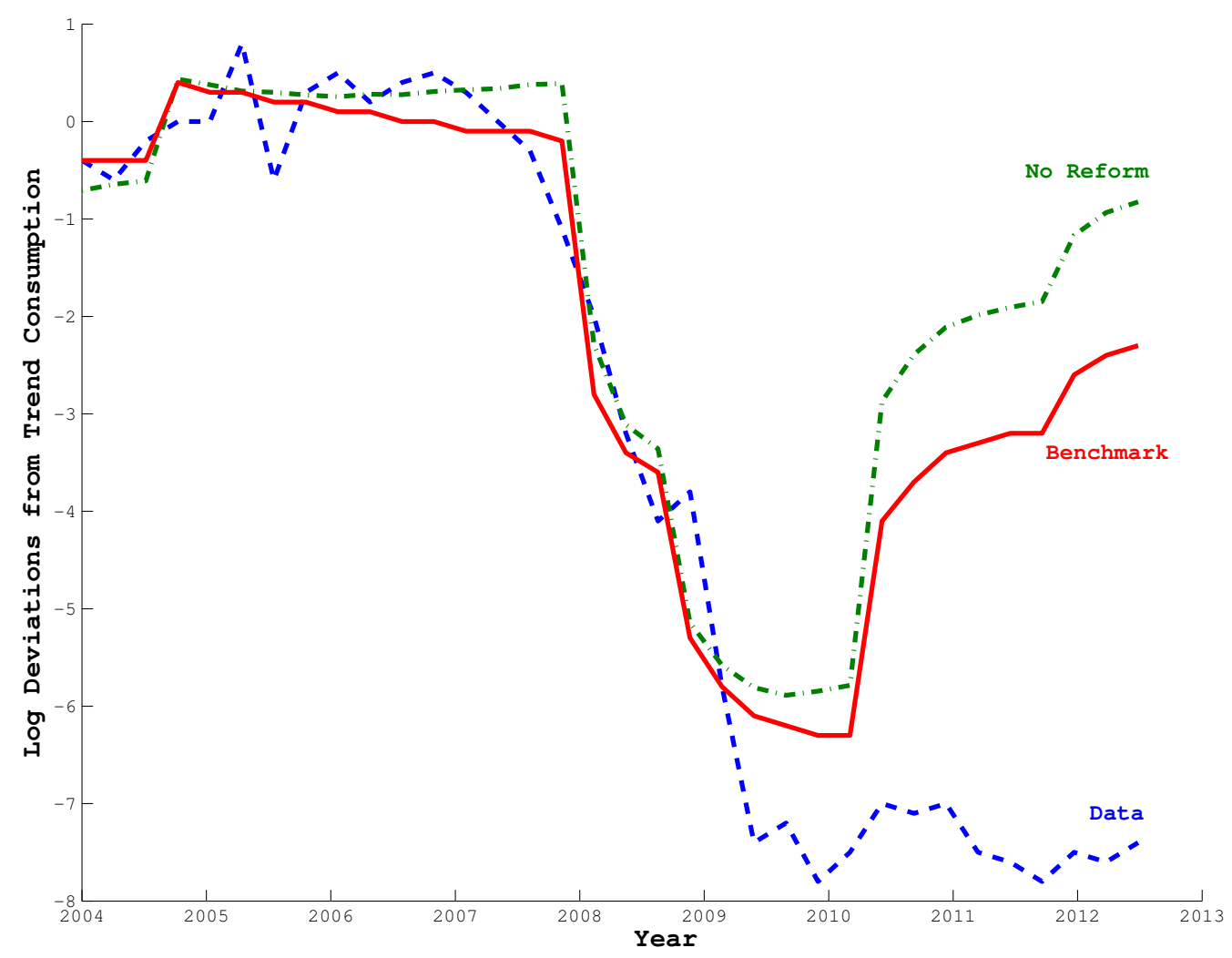


Figure 20: Aggregate Income

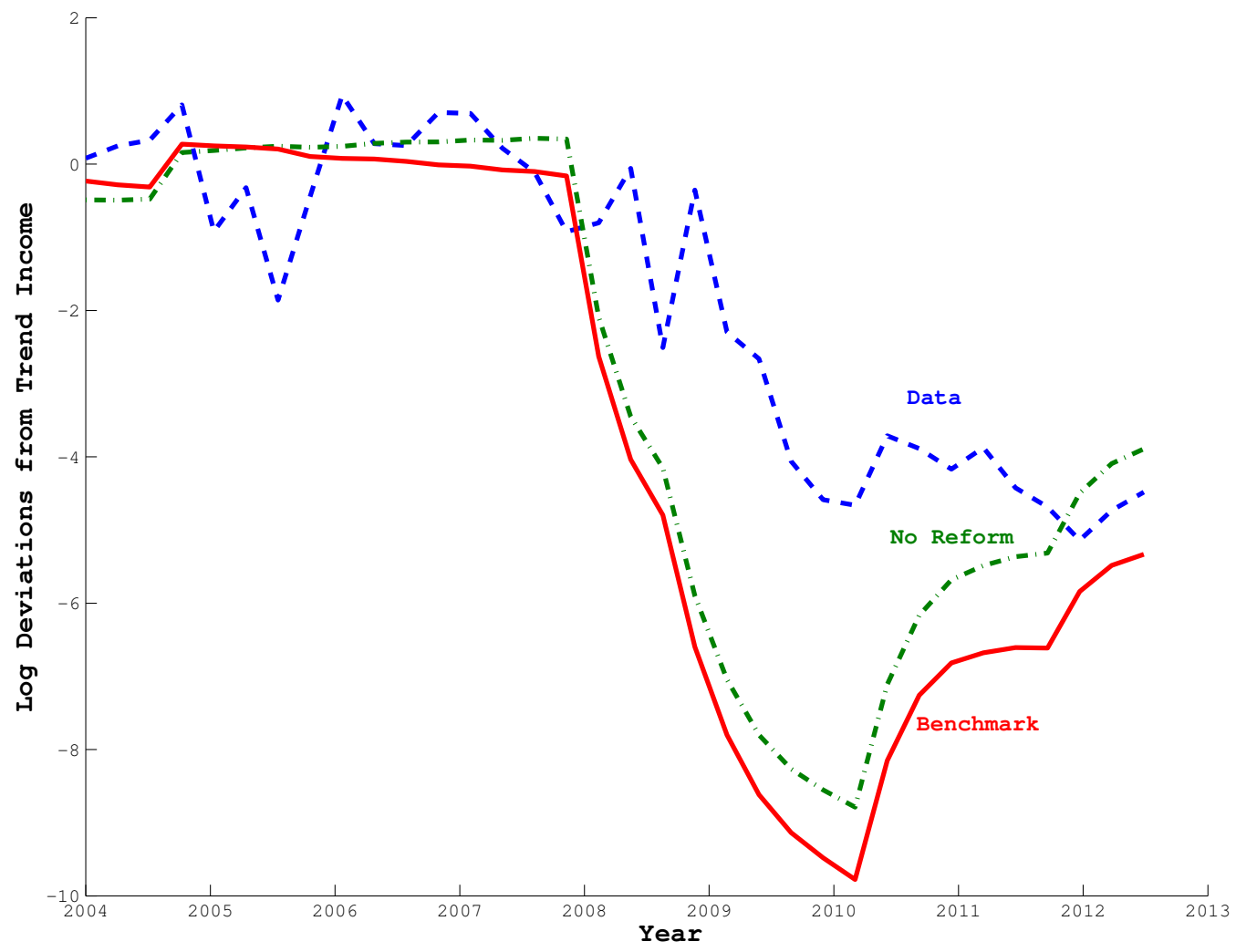

